\title{
The 3D Brain Unit Network Model to Study Spatial Brain Drug Exposure under Healthy and Pathological Conditions
}

\author{
Esmée Vendel $^{\prime} \cdot$ Vivi Rottschäfer ${ }^{\prime}$ • Elizabeth C.M. de Lange ${ }^{2}$ (D)
}

Received: 26 September 2019 / Accepted: 9 January 2020 / Published online: 9 July 2020

(C) The Author(s) 2020

\begin{abstract}
Purpose We have developed a 3D brain unit network model to understand the spatial-temporal distribution of a drug within the brain under different (normal and disease) conditions. Our main aim is to study the impact of disease-induced changes in drug transport processes on spatial drug distribution within the brain extracellular fluid (ECF).

Methods The 3D brain unit network consists of multiple connected single 3D brain units in which the brain capillaries surround the brain ECF. The model includes the distribution of unbound drug within blood plasma, coupled with the distribution of drug within brain ECF and incorporates brain capillaryblood flow, passive paracellular and transcellular $\mathrm{BBB}$ transport, active BBB transport, brain ECF diffusion, brain ECF bulk flow, and specific and nonspecific brain tissue binding. All of these processes may change under disease conditions.
\end{abstract}

Results We show that the simulated disease-induced changes in brain tissue characteristics significantly affect drug concentrations within the brain ECF.

Conclusions We demonstrate that the 3D brain unit network model is an excellent tool to gain understanding in the

Electronic supplementary material The online version of this article (https://doi.org/I 0. I007/s I 1 095-020-2760-y) contains supplementary material, which is available to authorized users.

Vivi Rottschäfer

vivi@math.leidenuniv.nl

Elizabeth C.M. de Lange

ecmdelange@lacdr.leidenuniv.nl

Esmée Vendel

e.vendel@math.leidenuniv.nl

Mathematical Institute, Niels Bohrweg I, 2333CA,

Leiden, The Netherlands

2 Leiden Academic Center for Drug Research, Einsteinweg 55, 2333CC, Leiden, The Netherlands interdependencies of the factors governing spatial-temporal drug concentrations within the brain ECF. Additionally, the model helps in predicting the spatial-temporal brain ECF concentrations of existing drugs, under both normal and disease conditions.

KEY WORDS Brain extracellular fluid · pharmacokinetics . mathematical · model $\cdot$ drug binding · drug transport

\section{ABBREVIATIONS \\ BBB blood-brain barrier \\ brain ECF brain extracellular fluid \\ PK pharmacokinetics}

\section{INTRODUCTION}

Insight into the spatial-temporal distribution of a drug within the brain is still limited, but very important for improved understanding of drug interaction with binding sites and ultimately drug effects and side effects. The blood-brain barrier $(\mathrm{BBB})$ is a major barrier of the brain and separates the blood plasma in the brain capillaries from the brain extracellular fluid (brain ECF). The BBB has great impact on the relationship between drug concentration-time profiles (pharmacokinetics; PK) within the blood plasma and the brain ECF (see i.e. (1)). However, there is a lack of understanding of the mechanisms that may lead to local differences of brain ECF PK.

Drug distribution within the brain ECF is governed by many factors, including blood plasma PK in the brain capillaries, BBB transport, diffusion, brain ECF bulk flow as well as by specific and non-specific binding, as reviewed in (2). All of these factors may be locally different, for example by disease. First, brain capillary density may increase as a consequence of certain brain 
diseases, like Huntington's disease (3,4), as the disease may induce new blood vessels to sprout, giving rise to a denser network of brain capillaries. On the other hand, brain capillary density may decrease by ageing (i.e $(5,6))$. Second, BBB transport may be affected under particular (disease) conditions. In many neurological diseases, disruption of the tight junctions leads to an increase in BBB transport of drugs that normally are impeded in their transport across the paracellular route (i.e. small hydrophilic drugs). In addition, expression and/or functionality of active (influx and efflux) transporters may be higher or lower, see (7) for a recent review on this topic. Third, brain ECF diffusion and bulk flow may be hindered by local disease: as a consequence of BBB disruption (by disease conditions), blood-derived cells and debris may leak into the brain ECF. The presence of these cells and debris within the brain ECF hinders diffusion within the brain ECF and interrupts the generation of brain ECF bulk flow (7). Finally, the density of specific and non-specific binding sites may differ per location within the brain (see e.g. (8) or Allen Brain Atlas for examples on concentrations of specific binding sites (receptors) at different locations within the (mouse) brain).

In order to increase our understanding of drug distribution within the brain in health and disease conditions, we have developed a 3D network of single brain units that includes the brain capillary blood flow, passive (paracellular and transcellular) and active BBB transport, diffusion, brain ECF bulk flow and binding kinetics. The model builds on a single brain unit model that has recently been developed in 2D (9) and 3D (Vendel 2019, submitted to PLOS ONE). The 3D brain unit network consists of multiple connected 3D brain units, see Fig. 1 (left). This network is an improved representation of reality, because a) the brain capillaries are interconnected, and b) some brain capillaries are located more closely to the larger blood vessels (the arteriole and the venule) than others. Importantly, the network representation allows for the study of differences within the network, where one 3D brain unit may be assigned different properties (e.g. a higher specific binding site concentration) than another unit. Our model allows for the prediction of drug concentrations at any position within the 3D brain unit network, thereby providing insights into the spatial distribution of a drug within the brain. In this manuscript, we study the effects of brain capillary density, BBB transport, brain ECF diffusion and binding site density on drug distribution within the 3D brain unit network. We study the effect of local changes in these processes of brain drug distribution, as may occur in disease conditions or by differences in location within the brain, on drug distribution within the $3 \mathrm{D}$ brain unit network. To investigate how spatial drug distribution is affected by disease-induced changes in brain drug distribution processes, we compare drug distribution in a $3 \mathrm{D}$ brain unit network with 'reference' parameter values to drug distribution in a network with parameters that are different because of particular disease aspects. Below, in section 2, we first describe the $3 \mathrm{D}$ brain unit network and all the properties assigned to it. In section 3, we study drug distribution within the 3D brain unit network in health and disease conditions and in different locations within the brain. Finally, in section 4, we discuss and conclude our work.

\section{THE 3D BRAIN UNIT NETWORK MODEL}

We build a network of multiple connected single 3D brain units, based on the recent 3D brain unit model (submitted to
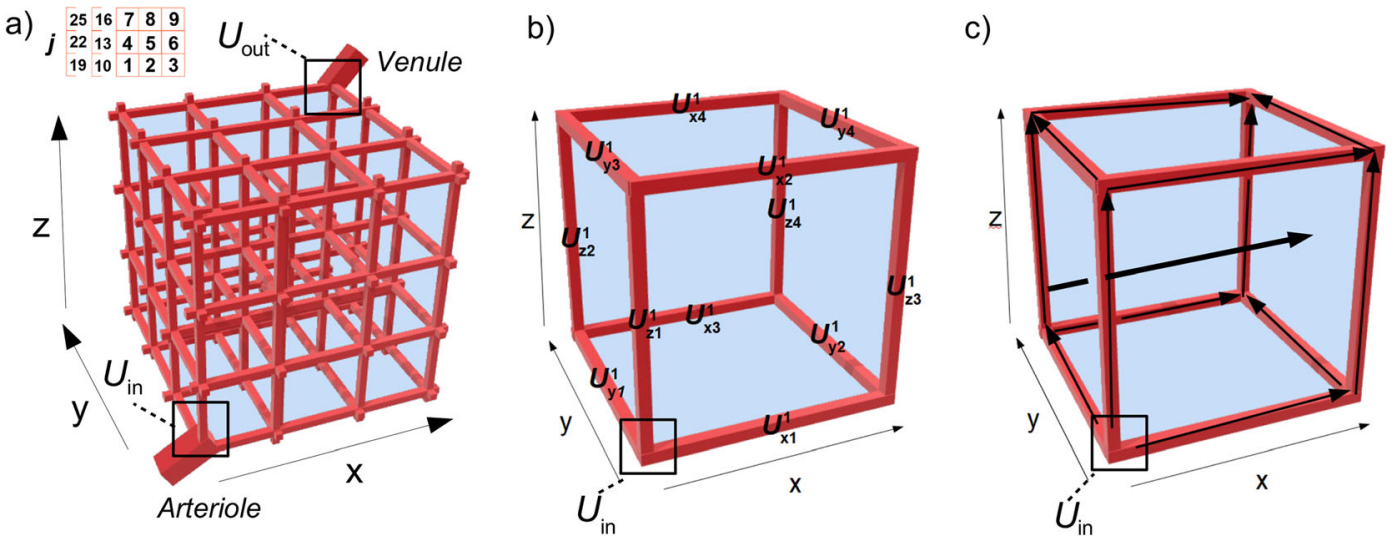

Fig. I Sketch of the 3D model brain unit network. (a) The 3D brain unit network. The brain unit network consists of $N 3$ single brain units. Here, $N=3$. The single brain units are numbered $\mathrm{j}=1-\mathrm{N}^{3}$ (inset). In each brain unit, the brain capillaries surround the brain ECF. The brain capillaries (red) surround the brain ECF (blue) and denote the border of each unit. The brain capillaries are linked to an incoming arteriole and a draining venule. (b) The left front bottom 3D single brain unit is shown as an example as part of the $3 \mathrm{D}$ brain unit network. This unit consists of a blood-plasma-domain, which is contained in $U_{\mathrm{pl}}$ (red) and a brain-ECFdomain, contained in UECF (blue). The blood-plasma-domain is divided into several sub-domains: $U_{\text {in }}$ is the domain where the dose of absorbed drug enters the

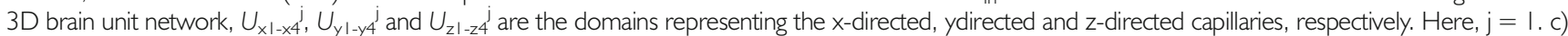
Transport directions in the model. From Uin, drug is transported through the brain capillaries by the brain capillary blood flow in the direction indicated by the small arrows. Drug in the brain capillary blood plasma exchanges with the brain ECF by crossing the BBB. Drug within the brain ECF is, next to diffusion, transported by brain ECF bulk flow (indicated by the bold arrow). 
PLOS ONE). The model describes drug distribution within a cubic domain that represents a piece of brain tissue. It includes the distribution of unbound drug within the blood plasma, coupled with the distribution of drug within the brain ECF and incorporates the brain capillar blood flow, passive paracellular and transcellular BBB transport, active BBB transport, drug diffusion and bulk flow within the brain ECF and the kinetics of drug binding to specific and non-specific binding sites. Here, we briefly summarize the 3D brain unit network model and, for full details, we refer to our earlier 3D brain unit model. The 3D brain unit network consists of multiple connected single 3D brain units. Each 3D brain unit is a cube, in which the brain capillaries surround the brain ECF. The brain capillaries within the network are linked to an incoming arteriole and a draining venule (Fig. 1a). From each brain capillary, drug is transported across the BBB into the brain ECF of all neighbouring 3D brain units. Drug within the brain ECF is transported by diffusion and bulk flow and freely exchanges between units. All assumptions made for the 3D brain unit network model are listed in Table 1.

\section{Model Formulation of the 3D Brain Unit Network}

The $3 \mathrm{D}$ brain unit network is defined by a network of $\mathrm{N}^{3}$ brain units $U=\left\{(\mathrm{x}, \mathrm{y}, \mathrm{z}) \in \mathrm{R}^{3} \mid 0 \leq \mathrm{x} \leq \mathrm{Nx}_{\mathrm{r}} \wedge 0 \leq \mathrm{y} \leq \mathrm{Ny}_{\mathrm{r}} \wedge 0 \leq \mathrm{z} \leq\right.$ $\mathrm{Nz}_{\mathrm{r}}$ \}. The constants $\mathrm{x}_{\mathrm{r}}, \mathrm{y}_{\mathrm{r}}$ and $\mathrm{z}_{\mathrm{r}}$ represent the length of one unit, which is defined as $d_{\text {cap }}+2 r$, with $d_{\text {cap }}$ the brain intercapillary distance and $r$ the brain capillary radius. The total length of the $3 \mathrm{D}$ brain unit network is given by $\mathrm{N} d_{\text {cap }}+2 \mathrm{~N} r$. Capillary segments are defined for each 3D brain unit, see Fig. 1b. Each segment is named in the form $U_{\mathrm{xi}}^{\dot{j}}$, where $\mathrm{j}$ indicates unit number (see Fig. Figure 1a, inset) and xi indicates the capillary segment. For example, $U^{1}{ }_{x 1}$ describes capillary segment $\mathrm{x} 1$ in unit 1 . In the current 3D brain unit network model, capillary segments of adjacent units are part of the same capillary. For instance, $U_{\mathrm{y} 4}^{1}, U_{\mathrm{y} 3}^{2}, U_{\mathrm{y} 2}^{4}$ and $U_{\mathrm{y} 1}^{5}$ belong to the same capillary.

Within the brain capillaries, diffusion is assumed to be negligible compared to the blood flow (Table 1). Therefore, within each capillary, drug is only transported in the direction of the flow. The brain ECF is continuous and brain ECF drug exchange between units occurs by diffusion (in all directions) and brain ECF bulk flow (in the x-direction only). The domain $U$ is divided into the subsets $U_{\mathrm{pl}} \subset U, U_{\mathrm{BBB}} \subset U$ and $U_{\mathrm{ECF}} \subset$ $U$, representing the brain capillaries, the $\mathrm{BBB}$ and the brain ECF, respectively, such that $U=U_{\mathrm{pl}} \cup U_{\mathrm{BBB}} \cup U_{\mathrm{ECF}}$ Within $U_{\mathrm{pl}}$ we define the concentration of (unbound) drug by $C_{\mathrm{pl}}$. Within $U_{\mathrm{ECF}}$, we define the brain ECF concentrations of unbound drug, drug bound to specific binding sites and drug bound to non-specific sites by $C_{\mathrm{ECF}}, B_{1}$ and $B_{2}$.

\section{Description of Drug Distribution in $U_{\mathbf{p l}}$}

We define the concentration of (unbound) drug within $U_{\text {in }}$ as:

$C_{\mathrm{pl}}=\frac{F k_{\mathrm{a}} \text { Dose }}{V_{\mathrm{d}}\left(k_{\mathrm{a}}-k_{\mathrm{e}}\right)}\left(\mathrm{e}^{-k_{\mathrm{e}} \mathrm{t}}-\mathrm{e}^{-k_{\mathrm{a}} \mathrm{t}}\right)$ for $C_{\mathrm{pl}} \in U_{\text {in }}$

where $\mathrm{F}$ is the drug bio-availability, $k_{\mathrm{a}}$ the drug absorption rate constant, $k_{\mathrm{e}}$ the drug elimination rate constant, Dose the molar amount of orally administered drug, and $V_{\mathrm{d}}$ the drug distribution volume. This definition includes parameters related to oral administration. In case of single intravenous administration, all drug directly enters the blood.

Blood carrying the drug enters the 3D brain unit network in $U_{\text {in }}$ and flows from there in the x-direction, y-direction and z-direction towards $U_{\text {out }}$ (see Fig. 1c). We define:

$$
\begin{aligned}
\frac{\partial C_{\mathrm{pl}}}{d \mathrm{t}} & =-v_{\mathrm{blood}} \frac{\partial C_{\mathrm{pl}}}{\partial \mathrm{x}} \text { for } C_{\mathrm{pl}} \in U_{x i}^{j}, \text { for } i=1, . ., 4 \text { and } j \\
& =1, . ., \mathcal{N}^{3}
\end{aligned}
$$

$$
\begin{aligned}
\frac{\partial C_{\mathrm{pl}}}{d \mathrm{t}} & =-v_{\text {blood }} \frac{\partial C_{\mathrm{pl}}}{\partial \mathrm{y}} \text { for } C_{\mathrm{pl}} \in U_{y i}^{j}, \text { for } i=1, . ., 4 \text { and } j \\
& =1, . ., \mathcal{N}^{3} .
\end{aligned}
$$

Table I Model Assumptions

\begin{tabular}{ll}
\hline Brain capillaries & All brain capillaries are equal in size and area. \\
The brain capillary blood flow velocity is constant in all brain capillaries. \\
Diffusion is negligible compared to the blood flow. \\
All drug is well mixed in the cross-capillary direction \\
All drug is in unbound state. \\
\hline Brain ECF & All drug within the brain distributes only within the brain ECF. \\
& The brain ECF bulk flow is unidirectional. In our model it points in the x-direction. \\
& Both specific and non-specific binding sites are exposed to brain ECF. \\
& Both specific and non-specific binding sites are evenly distributed over the 3D brain unit network without changing position. \\
& Drug binding is reversible.
\end{tabular}




$$
\begin{aligned}
\frac{\partial C_{\mathrm{pl}}}{d \mathrm{t}} & =-v_{\text {blood }} \frac{\partial C_{\mathrm{pl}}}{\partial \mathrm{z}} \text { for } C_{\mathrm{pl}} \in U_{z i}^{j}, \text { for } i=1, . ., 4 \text { and } j \\
& =1, . ., \mathcal{N}^{3}
\end{aligned}
$$

where vblood is the blood flow velocity within the brain capillaries and where the initial condition is given by

$C_{p l}(\mathrm{x}, \mathrm{y}, \mathrm{z}, \mathrm{t}=0)=0$

\section{Description of Drug Distribution in $U_{\mathrm{ECF}}$}

We describe the distribution of unbound and bound drug within $U_{\mathrm{ECF}}$ with the following system of equations:

$$
\begin{aligned}
& \frac{\partial C_{\mathrm{ECF}}}{\partial \mathrm{t}}=D^{*} \nabla^{2} C_{\mathrm{ECF}}-v_{\mathrm{ECF}} \frac{\partial C_{\mathrm{ECF}}}{\partial x}-k_{\text {|on }} C_{\mathrm{ECF}}\left(B_{\mid}^{\max }-B_{\mid}\right)+k_{\text {off }} B_{\mid} \\
& -k_{2 \text { on }} C_{\mathrm{ECF}}\left(B_{2}^{\max }-B_{2}\right)+k_{2 \text { off }} B_{2} \\
& \frac{\partial B_{1}}{\partial \mathrm{t}}=k_{\text {। }} C_{\mathrm{ECF}}\left(B_{\mid}^{\max }-B_{1}\right)-k_{\text {।off }} B_{1} \\
& \frac{\partial B_{2}}{\partial \mathrm{t}}=k_{2 \mathrm{on}} C_{\mathrm{ECF}}\left(B_{2}^{\max }-B_{2}\right)-k_{2 \text { off }} B_{2}
\end{aligned}
$$

with initial conditions

$$
C_{E C F}(\mathrm{x}, \mathrm{y}, \mathrm{z}, \mathrm{t}=0)=0,
$$

$B_{i}(\mathrm{x}, \mathrm{y}, \mathrm{z}, \mathrm{t}=0)=0, i=1,2$,

with $\mathrm{D}^{*}=\frac{D}{\lambda^{2}}$, where $D$ is the diffusion coefficient in a free medium and $\lambda$ the tortuosity, $v$ ECF the ( $\mathrm{x}$-directed) brain ECF bulk flow velocity, $B_{1}{ }^{\max }$ the total concentration of specific binding sites, $k_{1 \text { on }}$ the association rate constant for specific binding, $k_{\text {loff }}$ the dissociation rate constant for specific binding, $B_{2}^{\max }$ the total concentration of non-specific binding sites, $k_{2 o n}$ the association rate constant for non-specific binding and $k_{2 \text { off }}$ the dissociation rate constant for non-specific binding.

\section{Boundary Conditions}

We describe drug transport across the BBB as follows:

$$
\begin{aligned}
\mathrm{f}(\mathrm{u}, \mathrm{v})= & P(\mathrm{u}-\mathrm{v}) \\
& +\frac{T_{\mathrm{m}-\text { in }}}{S A_{\mathrm{BBB}}\left(\mathrm{K}_{\mathrm{m}-\text { in }}+\mathrm{u}\right)} \mathrm{u}-\frac{T_{\mathrm{m}-\text { out }}}{S A_{\mathrm{BBB}}\left(\mathrm{K}_{\mathrm{m}-\text { out }}+\mathrm{v}\right)} \mathrm{v}
\end{aligned}
$$

with $\mathrm{u}=C_{\mathrm{pl}}, \mathrm{v}=C_{\mathrm{ECF}}, P$ the $\mathrm{BBB}$ permeability, $T_{\mathrm{m} \text {-in }}$ the maximum rate of active influx, $T_{\text {m-out }}$ the maximum rate of active efflux, $K_{\mathrm{m} \text {-in }}$ the concentration of drug at which half of $T_{\mathrm{m} \text {-in }}$ is reached, $K_{\mathrm{m} \text {-out }}$ the concentration of drug at which half of $T_{\text {m-out }}$ is reached and $S A_{\mathrm{BBB}}$ a correction factor taking the BBB surface area into account.

Based on expression (9), BBB transport of unbound drug into $U_{\mathrm{ECF}}$ is described with (example for the x direction):

$$
\begin{aligned}
-D * \frac{\partial C_{\mathrm{ECF}}}{\partial x} & =\mathrm{f}\left(C_{\mathrm{pl}}, \mathrm{C}_{\mathrm{ECF}}\right), \text { for }(\mathrm{x}, \mathrm{y}, \mathrm{z}) \in U_{\mathrm{BBB}}, \text { at } \mathrm{x} \\
& =\mathrm{r}+\mathrm{n}\left(\mathrm{x}_{\mathrm{r}}+2_{\mathrm{r}}\right), \text { for } \mathrm{n}=0, \ldots, \mathrm{N}-1 \\
D^{*} \frac{\partial C_{\mathrm{ECF}}}{\partial x}= & \mathrm{f}\left(\mathrm{C}_{\mathrm{pl}}, \mathrm{C}_{\mathrm{ECF}}\right), \text { for }(\mathrm{x}, \mathrm{y}, \mathrm{z}) \in U_{\mathrm{BBB}} \text { at } \mathrm{x} \\
= & \mathrm{r}+\mathrm{n}\left(\mathrm{x}_{\mathrm{r}}+2 r\right), \text { for } n=1, \ldots, \mathcal{N} .
\end{aligned}
$$

For drug transport into $U_{\mathrm{pl}}$, we use the reverse of expres$\operatorname{sion}(10)$.

We describe drug concentrations at the sides of $U_{\mathrm{pl}}$ and $\mathrm{U}_{\mathrm{ECF}}$ with no-flux boundary conditions. At the sides of $U_{\mathrm{pl}}$,we describe drug concentrations with (example for the $\mathrm{x}$ direction):

$\frac{\partial C_{\mathrm{pl}}}{\partial \mathrm{x}}=0$

for $(\mathrm{x}, \mathrm{y}, \mathrm{z}) \in U_{\mathrm{pl}} \backslash U_{\text {out }} \cap \partial U$, for $\mathrm{x}=0$ and $\mathrm{x}=\mathrm{Nx}_{\mathrm{r}}$.

At the sides of $U_{\mathrm{ECF}}$, we describe drug concentrations with:

$n \cdot \nabla C_{\mathrm{ECF}=0 \text { for }(\mathrm{x}, \mathrm{y}, \mathrm{z}) \in U_{\mathrm{ECF}} \cap \partial U}$

where $\mathrm{n}$ is the normal vector on $U_{E C F} \cap \partial U$.

\section{Model Parameter Values and Units}

The 3D brain unit network model dimensions are, like for the previous brain unit model (9), based on the properties of the rat brain. Within the 3D brain unit network, blood plasma PK is described using eqs. (1)-(5) with boundary conditions described in eqs. (10)-(12), while brain ECF PK is described with eqs. (6)-(8) with boundary conditions described in (10) and (13).

For our model analysis, we use, unless otherwise indicated, parameter values that are in the middle of the physiological ranges given in Table 2 (see also (9)). The reference parameter values of the drug are given in Table 3. These values, as shown in Table 3, are used in all simulations, unless stated differently. The parameter values may depend on their $(\mathrm{x}, \mathrm{y}, \mathrm{z})$-position within the 3D brain unit network. For example, in section 3.3, $\mathrm{B}_{1}{ }^{\max }$ varies per unit and is assigned different values depending on the position within the $3 \mathrm{D}$ brain unit network. 
Table 2 The Reference 3D Brain unit Model Parameters and their Units, for Rat Brain

\begin{tabular}{|c|c|c|}
\hline Parameter & Unit & Value range \\
\hline F, bioavailability & - & $0-1$ \\
\hline Dose & $\mu \mathrm{mol}$ & $10^{-1}-5 \cdot 10^{3}$ \\
\hline V, distribution volume & L & $3-5 \cdot 10^{3}$ \\
\hline$k_{\mathrm{a}}$, absorption rate constant & $s^{-1}$ & $0-2 \cdot 10^{-3}$ \\
\hline$k_{e}$, elimination rate constant & $s^{-1}$ & $10^{-1}-5 \cdot 10^{-3}$ \\
\hline$d_{\text {cap }}$, intercapillary distance & $\mathrm{m}$ & $2 \cdot 10^{-5}-7 \cdot 10^{-5}$ \\
\hline$r$, brain capillary radius & $\mathrm{m}$ & $0.8-4.8 \cdot 10^{-6}$ \\
\hline$V_{\text {blood, }}$ brain capillary blood flow velocity & $\mathrm{m} \mathrm{s}^{-1}$ & $0.5-50 \cdot 10^{-4}$ \\
\hline$D^{*}=\frac{D}{\lambda^{2}}$, effective diffusion coefficient & $m^{2} s^{-1}$ & $10^{-11}-10^{-10}$ \\
\hline$V_{E C F}$ brain ECF bulk flow velocity & $\mathrm{ms}^{-1}$ & $5 \cdot 10^{-8}-5 \cdot 10^{-6}$ \\
\hline P, 3D passive BBB permeability ${ }^{a}$ & $\mathrm{~m} \mathrm{~s}^{-1}$ & $10^{-10}-10^{-5}$ \\
\hline$T_{m-\text { in }}$, maximal active influx rate & $\mu \mathrm{mol} \mathrm{s}{ }^{-1}$ & $10^{-8}-10^{-5}$ \\
\hline$K_{m-i n}$, concentration needed to reach half of $T_{m-i n}$ & $\mu \mathrm{mol} \mathrm{L} \mathrm{L}^{-1}$ & $10^{1}-10^{4}$ \\
\hline$T_{m-\text { out }}$, maximal active efflux rate & $\mu \mathrm{mol} \mathrm{s}{ }^{-1}$ & $10^{-8}-10^{-5}$ \\
\hline$K_{m}$ - out, concentration needed to reach half of $T_{m}$ - out & $\mu \mathrm{mol} \mathrm{L}{ }^{-1}$ & $10^{1}-10^{4}$ \\
\hline$S A_{B B B}$, surface area of the BBB & $m^{2}$ & $1.25 \cdot 10^{-10}$ \\
\hline$B_{\mid}^{\max }$,total concentration specific binding sites & $\mu \mathrm{mol} \mathrm{L}{ }^{-1}$ & $1 \cdot 10^{-3}-5 \cdot 10^{-1}$ \\
\hline$k_{\text {Ion }}$, specific association constant & $\left(\mu \mathrm{mol} \mathrm{L}{ }^{-1} \mathrm{~s}\right)^{-1}$ & $10^{-4}-10^{2}$ \\
\hline$k_{\text {loff, specific dissociation constant }}$ & $s^{-1}$ & $10^{-6}-10^{1}$ \\
\hline$B_{2}^{\max }$, total non-specific binding sites & $\mu \mathrm{mol} \mathrm{L}^{-1}$ & $\mid \cdot 10^{1}-5 \cdot 10^{3}$ \\
\hline$k_{2 o n}$, non-specific association constant & $\left(\mu \mathrm{mol} \mathrm{L} \mathrm{L}^{-1} \mathrm{~s}\right)^{-1}$ & $10^{-6}-10^{1}$ \\
\hline$k_{2 o f f}$ non-specific dissociation constant & $s^{-1}$ & $10^{-4}-10^{3}$ \\
\hline
\end{tabular}

The physiological range of values of the parameters is given. These are based on references from the literature, see (9) for references

${ }^{a}$ This value is the apparent (experimentally measured) overall passive permeability

\section{MODEL RESULTS}

Prior to model analysis, the system of equations and boundary conditions are nondimensionalised by scaling all variables by the typical scales given in Table 3 (see Appendix 1 for details). Then, the nondimensionalised system is spatially discretised with a well-established numerical procedure using finite element approximations (10). The results are presented using the parameters with dimensions. The simulation output includes the concentrations of free, specifically bound and nonspecifically bound drug, given in $\mu \mathrm{mol} \mathrm{L}^{-1}$ overtime.

In the following sections, we compare a 3D brain unit network with default properties, i.e. with parameter values corresponding to the reference values given in Table 3 ('normal condition'), to a 3D brain unit network with other properties, as may be induced by disease conditions (i.e. disruption of BBB transport) or location (i.e. a binding site density that differs per location), see Fig. 2. There, local differences may also exist within the 3D brain unit network, i.e. specific binding sites may be concentrated within a particular area of the network, see Fig. 2 (right). We show the impact of brain capillary density (section 3.1), disruption of BBB transport (section 3.2) and differences in drug target concentrations (section 3.3) on local drug concentrations and drug distribution within the brain ECF (brain ECF PK). In section 3.4 we vary multiple properties and study their (combined) effect on drug concentrations within the brain ECF. In sections 3.2-3.4, we summarize the PK for each situation by the maximal attained concentration, $C_{\max }$, and $t_{\max }$ (time needed to attain $C_{\max }$ ) at various points in the network. We use $C_{\max , \mathrm{ECF}}, C_{\max , \mathrm{B} 1}, t_{\max , \mathrm{ECF}}$ and $t_{\max , \mathrm{B} 1}$ for the $C_{\max }$ and $t_{\max }$ of $C_{\mathrm{ECF}}$ and $B_{1}$, respectively. Distribution plots of the drug are given for crosssections of the $3 \mathrm{D}$ brain unit network for various times.

\section{Simulated Changes in Brain Capillary Density}

We evaluate the effect of brain capillary density on drug concentrations within the brain ECF. In Fig. 3, example geometries of 3D networks with different brain capillary densities are shown. There, brain capillary density is changed by varying $d_{\text {cap }}$, while we leave the total size of the network unchanged. 
Table 3 3D Brain Unit Model Reference Parameters and their Units

\begin{tabular}{|c|c|c|}
\hline Parameter & Unit & Value \\
\hline$N$ & - & $3 \cdot 10^{0}$ \\
\hline$F$ & - & $1 \cdot 10^{\circ}$ \\
\hline Dose & $\mu \mathrm{mol}$ & $50 \cdot 10^{\circ}$ \\
\hline$k_{a}$ & $s^{-1}$ & $2 \cdot 10^{-4}$ \\
\hline$k_{\mathrm{e}}$ & $s^{-1}$ & $5 \cdot 10^{-5}$ \\
\hline V & $\mathrm{L}$ & $2 \cdot 10^{1}$ \\
\hline$d_{\text {cap }}$ & $\mathrm{m}$ & $50 \cdot 10^{-6}$ \\
\hline r & $\mathrm{m}$ & $2.5 \cdot 10^{-6}$ \\
\hline Vblood & $\mathrm{ms}^{-1}$ & $5 \cdot 10^{-4}$ \\
\hline$D^{*}=\frac{D}{\lambda}$ & $m^{2} s^{-1}$ & $0.510^{-10}$ \\
\hline$v_{E C F}$ & $m^{s-1}$ & $0.5 \cdot 10^{-6}$ \\
\hline$P$ & $\mathrm{~m} \mathrm{~s}^{-1}$ & $1 \cdot 10^{-8}$ \\
\hline$T_{m-\text { in }}$ & $\mu \mathrm{mol} \mathrm{s}{ }^{-1}$ & $1 \cdot 10^{-7}$ \\
\hline$K_{m-i n}$ & $\mu \mathrm{mol} \mathrm{L} \mathrm{L}^{-1}$ & $1 \cdot 10^{2}$ \\
\hline$T_{\text {m-out }}$ & $\mu \mathrm{mol} \mathrm{s}^{-1}$ & $1 \cdot 10^{-7}$ \\
\hline$K_{\text {m-out }}$ & $\mu \mathrm{mol} \mathrm{L}^{-1}$ & $1 \cdot 10^{2}$ \\
\hline$S A_{B B B}$ & $m^{2}$ & $1 \cdot 10^{-10}$ \\
\hline$B_{\mid}^{\max }$ & $\mu \mathrm{mol} \mathrm{L}{ }^{-1}$ & $5 \cdot 10^{-2}$ \\
\hline$k_{\text {lon }}$ & $\left(\mu \mathrm{mol} \mathrm{L}{ }^{-1} \mathrm{~s}\right)^{-1}$ & $1 \cdot 10^{\circ}$ \\
\hline$k_{\text {loff }}$ & $s^{-1}$ & $1 \cdot 10^{-2}$ \\
\hline$B_{\mid}^{\max }$ & $\mu \mathrm{mol} \mathrm{L} \mathrm{L}^{-1}$ & $5 \cdot 10^{1}$ \\
\hline$k_{2 o n}$ & $\left(\mu \mathrm{mol} \mathrm{L}{ }^{-1} \mathrm{~s}\right)^{-1}$ & $1 \cdot 10^{-2}$ \\
\hline$k_{2 \text { off }}$ & $s^{-1}$ & $1 \cdot 10^{-0}$ \\
\hline
\end{tabular}

Figure 4 shows the effects of brain capillary density on $C_{\mathrm{ECF}}$ for different values of the passive BBB permeability, $P$. For proper comparison, $C_{\mathrm{ECF}}$ is measured on similar points for all brain capillary densities: in the middle of the right upper back unit, which is the unit next to the venule. When $P$ is set at its reference value $\left(P=0.1 \cdot 10^{-7} \mathrm{~m} \mathrm{~s}^{-1}\right.$, as in Table 3$), C_{\mathrm{ECF}}$ increases with brain capillary density: with a higher brain capillary density, higher values of $C_{\mathrm{ECF}}$ are attained at earlier times. Moreover, $C_{\mathrm{ECF}}$ decreases more quickly when the brain capillary density is high than when it is low. On the other hand, when $P$ is high $\left(P=1 \cdot 10^{-7} \mathrm{~m} \mathrm{~s}^{-1}\right)$, brain capillary density hardly affects $C_{\mathrm{ECF}}$ (Fig. 4, right): a decrease in brain capillary density leads to an only slightly lower value of $C_{\text {max,ECF }}$ and an only slightly higher value of $t_{\text {max,ECF, while }}$ an increase in brain capillary density has no effect. This can be intuitively explained: with a high BBB permeability, drug quickly equilibrates between blood plasma and brain ECF as if it were one domain. In contrast, with a low permeability, exchange between blood plasma and brain ECF is limited and drug equilibration is slow. Then, the brain capillary density, and the increase in brain capillary surface, increases the extent of drug within the blood plasma that can be presented to the brain ECF.

\section{Simulated BBB Functionality in Health and Disease Conditions}

Here, we study the effect of changes in parameters related to BBB transport on drug concentrations within the brain ECF. Table 4 summarizes how three types of BBB transport (passive (paracellular) transport, active influx and active efflux) are affected by changes in properties as induced by a few common brain diseases. Increases in passive (paracellular) BBB transport occur in all listed brain diseases. In addition, BBB active influx and efflux may increase or decrease under disease conditions. The areas of the brain that are affected differ per disease condition, as is summarized in Table 5 . It is important to note that the effect of disease-induced changes in BBB permeability on drug concentrations within the brain ECF also depends on the properties of the drug. An increase in passive (paracellular) BBB permeability mostly affects the transport of compounds that depend more on the paracellular route to get into and out of the brain. In addition, compounds that are not actively transported are unaffected by changes in active influx or active efflux.

To gain information on the effect of disease-induced changes in BBB permeability on brain ECF PK for all types of drugs, we have studied the effect of all possible combinations of $P, T_{\mathrm{m} \text {-in }}$ and $T_{\mathrm{m} \text {-out }}$ on brain ECF PK within the $3 \mathrm{D}$ brain unit network model. There, brain ECF PK within the middle $3 \mathrm{D}$ brain unit is quantified by $C_{\max , \mathrm{ECF}}$ and $t_{\max , \mathrm{ECF}}$. A description of the main fundings of Table 6 is now given. An increase in $P$ generally correlates with an increase in $C_{\text {max }}$,ECF, except for when $T_{\mathrm{m} \text {-in }} \geq T_{\text {m-out }}$ and with $T_{\text {m-in }}>0.1-$ $10^{-7} \mu \mathrm{mol} \mathrm{s}^{-1}$, when an increase in $P$ correlates with a decrease in $C_{\text {max,EGF }}$. Acstive inux increases $C_{\text {max,EGF}}$, but has less effect when the $\mathrm{BBB}$ is highly spermeable to the drug, as drug can easily diffuse across the BBB back into the blood plasma. In similar fashion, active efflux decreases $C_{\text {max,ECF, }}$ but less so in the presence of a high value of $P$. Interestingly, in the presence of identical active transport rates $\left(T_{\mathrm{m}-\mathrm{in}}=T_{\mathrm{m}}\right.$ out $\neq 0), C_{\text {max }}$ ECF is larger compared to the reference' state with no active transport $\left(T_{\mathrm{m} \text {-in }}=0\right.$ and $\left.T_{\mathrm{m} \text {-out }}=0\right)$, except for when $T_{\text {m-in }}=T_{\text {m-out }}=0.1-10^{-7} \mathrm{~mol} \mathrm{~s}^{-1}$ and $P=1 \cdot 10^{-7} \mathrm{~m} \mathrm{~s}^{-1}$. BBB transport parameters also affect $t_{\text {max,ECF}}$. An increase in $P$ or increase in $T_{\text {m-out }}$ goes along with a smaller $t_{\text {max,EGF }}$ In contrast, the value of $T_{\mathrm{m} \text {-in }}$ hardly affects $t_{\text {max,ECF. }}$.

Next, we show the drug distribution within the 3D brain unit network for certain specific choices of parameters at $\mathrm{t}=50$. Figure 6 shows how changes in total BBB permeability and/or active influx affect $C_{\mathrm{ECF}}$. With a high value of $P$ and/or with a high value of $T_{\mathrm{m} \text {-in }}$, values of $C_{\mathrm{ECF}}$ increase. In the presence of active influx, local differences in $C_{\mathrm{ECF}}$ are seen: concentrations are slightly higher in the upper back than in the front brain units in the presence of active influx. In addition, values of $C_{\mathrm{ECF}}$ are higher at locations close to the blood plasma. Interestingly, in the presence of a high value of $P$, a high value of $T_{\text {m-in }}$ 


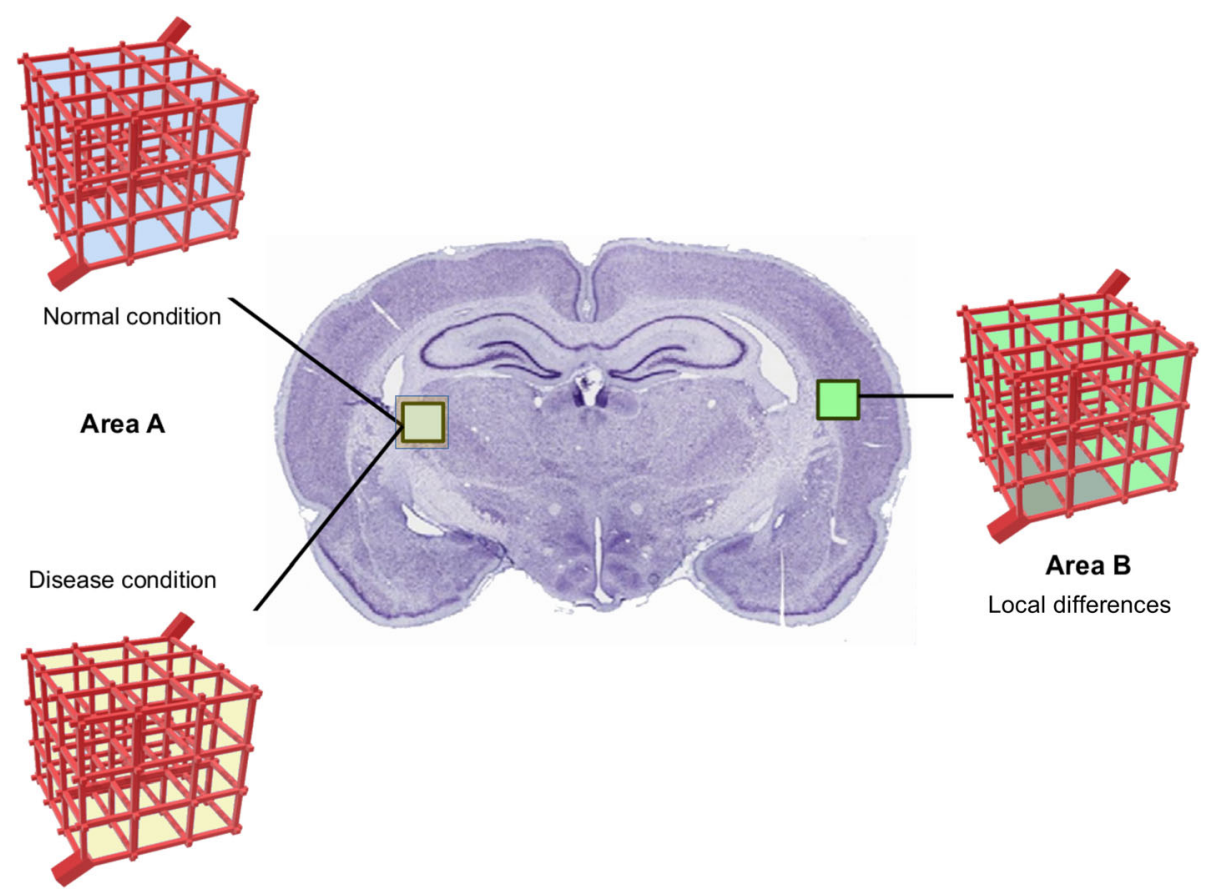

Fig. 2 The 3D brain unit network that may represent different areas of the rat brain. The brain unit network with reference properties, with parameter values corresponding to the reference values given in Table 3, (left top) represents a normal condition. The properties of the 3D brain unit network may change as a consequence of local disease (left bottom) or by differences in location (right). Local differences in properties may also exist within the 3D brain unit network, as shown on the right. There, the dark green area indicates an area with different properties (i.e. higher concentration of specific binding sites) than the surrounding area network, i.e. specific binding sites may be concentrated within a particular area of the network, see Fig. 2 (right). We show the impact of brain capillary density (section 3. I), disruption of BBB transport (section 3.2) and differences in drug target concentrations (section 3.3) on local drug concentrations and drug distribution within the brain ECF (brain ECF PK). In section 3.4 we vary multiple properties and study their (combined) effect on drug concentrations within the brain ECF. In sections 3.2-3.4, we summarize the PK for each situation by the maximal attained concentration, $C_{\max }$, and $t_{\max }$ (time needed to attain $C_{\max }$ ) at various points in the network. We use $C_{\max }, E C F, C_{\max }, \mathrm{BI}, t_{\max }, E C F$ and $t_{\max }, \mathrm{BI}$ for the $C_{\max }$ and $t_{\max }$ of $C_{\mathrm{ECF}}$ and $B_{1}$, respectively. Distribution plots of the drug are given for crosssections of the $3 \mathrm{D}$ brain unit network for various times.

decreases $C_{\mathrm{ECF}}$ (brighter blue colours in Fig. 7, bottom right). Fig. 7 shows the effect of changes in total BBB transport combined with changes in active efflux on $C_{\mathrm{ECF}}$. The presence of active efflux decreases $C_{\mathrm{ECF}}$. In case of a low value of $P, C_{\mathrm{ECF}}$ is already low and the effect of changes in $T_{\mathrm{m} \text {-out }}$ on $C_{\mathrm{ECF}}$ is negligible. Interestingly, in the presence of a high value of $P$ and a high value of $T_{\text {m-out }}$ (Fig. 7, bottom right), values of $C_{\mathrm{ECF}}$ increase within each unit in the direction of the brain EGF bulk flow. In conclusion, we have shown that an increase in BBB active influx, as may happen in Alzheimer's Disease, correlates with an increase in $C_{\max , \mathrm{ECF}}$, while an increase in BBB active efflux, as may happen in amyotrophic lateral sclerosis and epilepsy, correlates with a decrease in both $C_{\text {max }}$ ECF and $t_{\text {max,ECF. If }}$ both active influx and active efflux are affected, like may be the case in brain tumours, the effects on both $C_{\text {max }}$ ECF and $t_{\max }$,ECF depend on the rate of active influx and active efflux under healthy conditions and on the BBB
Fig. 3 Geometries of 3D brain unit networks with varying capillary density. Left: decreased brain capillary density, middle: reference brain capillary density, right: increased brain capillary density. The distances between the capillaries, $d_{\text {cap }}$ are set at $77.5,50$ and $36.25 \mu \mathrm{m}$.
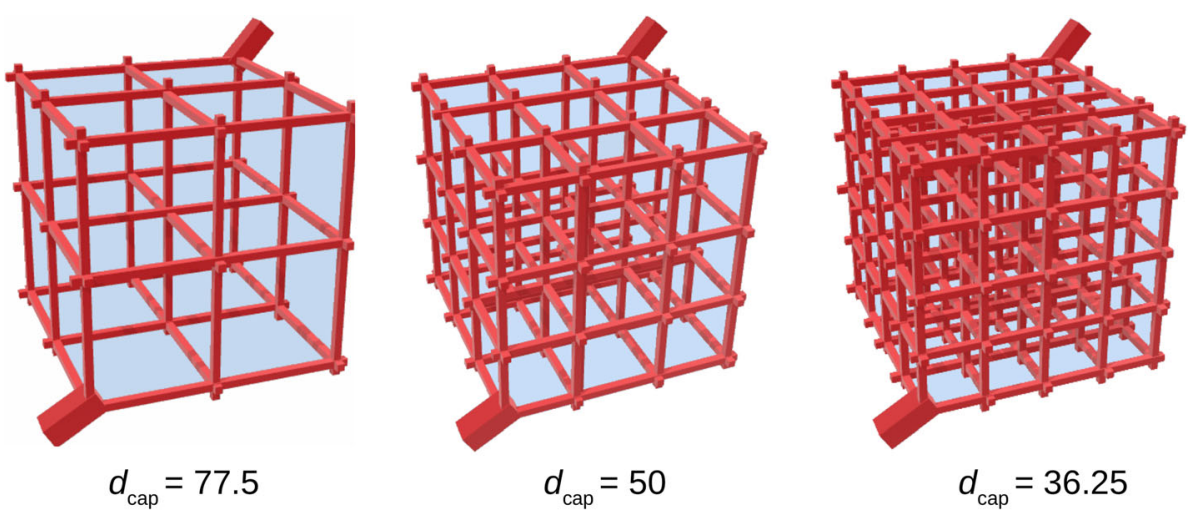


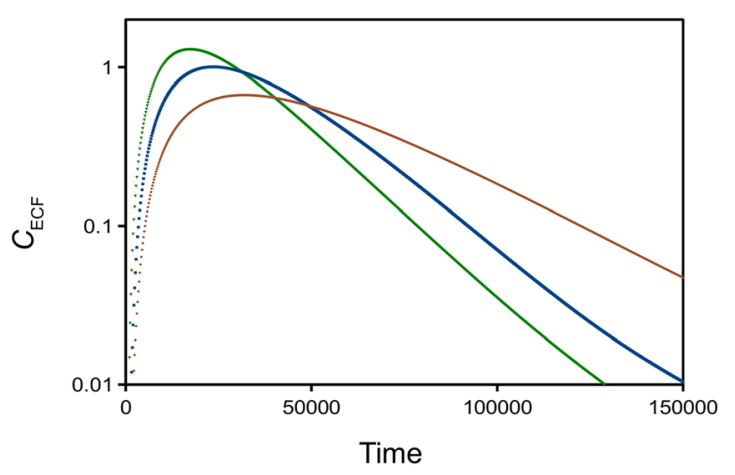

$P=0.1$

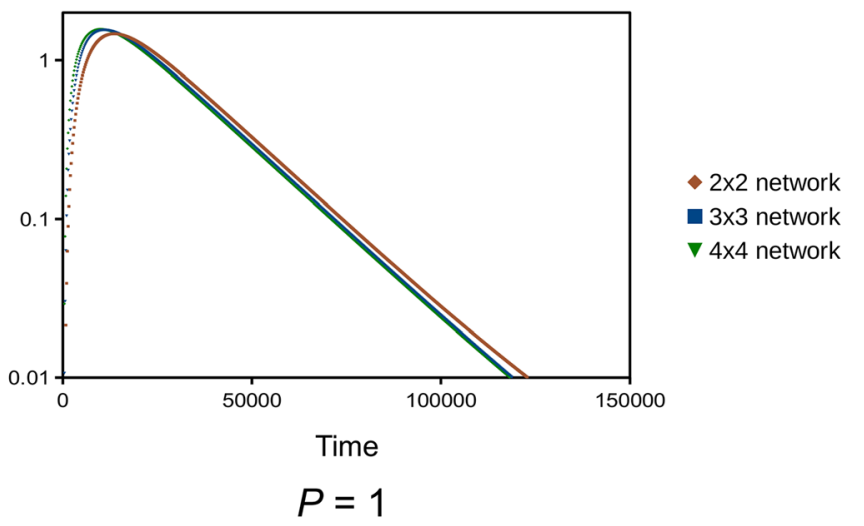

Fig. 4 Effects of brain capillary density on the concentration of unbound drug within the brain ECF. The BBB permeability $P$ is changed from $0.1 \cdot 10^{-7} \mathrm{~m} \mathrm{~s}^{-1}$ to $1 \cdot 10^{-7} \mathrm{~m} \mathrm{~s}^{-1}$, all other parameters are as in Table 3. $C_{E C F}$ is measured at the middle of the unit bordering $U_{\text {out }}$ in all configurations.

permeability. Increases in BBB (paracellular) permeability, as occurs in all mentioned brain diseases (Table 4) but has most impact on drugs that have difficulties crossing the $\mathrm{BBB}$, increases $C_{\text {max }}$ ECF and decreases $t_{\text {max }}$ ECF.

This also means that drugs that easily cross the BBB are less impacted by disease-induced changes in $\mathrm{BBB}$ permeability.

\section{Simulated Changes in Specific Binding Site Density}

Next, we study the effect of spatial differences in specific binding site (receptor) concentrations on brain ECF PK within the 3D brain unit network, which may represent different areas of the brain. Table 7 shows how concentration levels of various receptors differ over several brain areas. For example, dopamine receptor D2 (D2R) concentrations are generally highest

Table 4 Changes in Properties of the BBB as Reported in Health and Under Specific Disease Conditions

\begin{tabular}{llllllll}
\hline Process & AD & ALS & Epilepsy & MS & Stroke & Tumour & PD \\
\hline Passive transport & & & & & & & \\
(paracellular) & + & + & + & + & + & + & + \\
Active influx & + & $?$ & $?$ & $?$ & $?$ & + & $?$ \\
Active efflux & \pm & + & + & $?$ & - & + & $+/$ \\
\hline
\end{tabular}

See i.e. $(7,23)$ for some excellent reviews on this topic. It is shown how BBB trancellular transport, paracellular transport, active efflux and active efflux are affected in brain diseases compared to healthy conditions. There, no distinction is made between individual transporter types, but it is shown for active influx and active efflux in general. This is shown for Alzheimer's Disease (AD) (see i.e. $(11,12)$ ). amyotrophic lateral sclerosis (ALS) (see i.e. (I3)) epilepsy (I5), multiple sclerosis (MS) (16), Parkinson's Disease (PD) (17-19), stroke $(20,21)$ and tumour (i.e. (22)). A + indicates an increase of the extent of the $\mathrm{BBB}$ transport process that is associated with the disease, while a - indicates a decrease. $A \pm$ indicates that both increases and decreases have been observed as a consequence of the disease. Finally, a? indicates that diseaseinduced changes on the BBB transport process are not known in the striatum, while in the hippocampus, dopamine receptor concentrations are negligible.

To gain insight into the effect of (specific) binding site concentration on brain ECF PK for all types of drug, we first study the effect of all possible combinations of $B_{1}{ }^{\max }, k_{\text {lon }}$ and $k_{1 \text { off }}$ on brain ECF PK within the 3D brain unit network. Within the 3D brain unit network, we keep all parameters constant. Tables 8 and 9 summarize the PK for each situation by $C_{\text {max,EGF }}, t_{\max , \mathrm{ECF}}, C_{\max , \mathrm{B} 1}$, and $t_{\max , \mathrm{B} 1}$. We see that $C_{\text {max ECF }}$ and $t_{\text {max }}$ ECF are only affected by binding kinetics when $B_{1}{ }^{\max }$ is high (Tables 8 and 9). Then, $C_{\text {max ECF }}$ is smaller than the reference value. The extent of this decrease depends on the values of $k_{\text {lon }}$ and $k_{\text {loff }}$ : with increasing $k_{\text {lon }}, C_{\text {max }}$ ECF becomes lower, while with increasing $k_{\text {loff, }}, C_{\max , \mathrm{ECF}}$ becomes higher. Likewise, $t_{\max \text {,ECF }}$ generally increases with high $B_{1}{ }^{\max }$. It slightly decreases with higher $k_{1 \text { on }}$ when $\frac{k_{l_{\text {off }}}}{k_{10 n}} \geq 100$.

Obviously, $C_{\max , \mathrm{B} 1}$ is larger for higher values of $B_{1}{ }^{\max }$ (Table 9). Additionally, with a ratio of $\frac{k_{\text {off }}}{k_{10 n}} \geq 100, C_{\mathrm{max}, \mathrm{B} 1}$ is smaller than $B_{1}{ }^{\max }$. The value of $t_{\max }, \mathrm{B} 1$ decreases with higher $k_{\text {lon }}$ when $k_{\text {loff }}$ is low. It increases with higher $k_{\text {lon }}$ when $k_{\text {loff }}$ and $B_{1}{ }^{\max }$ are high (lower right corner). In most other cases

Table 5 Areas of the Brain, where the BBB is affected per Disease Condition

\begin{tabular}{|c|c|}
\hline Disease & Affected area \\
\hline$A D$ & Cortex and Hippocampus $(|\mathrm{I},| \mathrm{2})$ \\
\hline ALS & Medulla and Spinal Cord $(13,14)$ \\
\hline Epilepsy & Pariental gyrus and cortex (I5) \\
\hline MS & White matter (16) \\
\hline PD & Midbrain (I7), striatum (I8), subthalamic nucleus (19) \\
\hline Stroke & Site of stroke $(20,21)$ \\
\hline Tumour & Site of tumour (i.e. (22)) \\
\hline
\end{tabular}

$\mathrm{AD}=$ Alzheimer's disease, $\mathrm{MS}=$ multiple sclerosis, $\mathrm{ALS}=$ amyotrophic lateral sclerosis, PD = Parkinson's Disease. Adapted from (7) 
Table 6 Impact of BBB Transport Parameters on Brain ECF PK of Unbound Drug

\begin{tabular}{|c|c|c|c|c|c|c|c|c|c|c|c|c|}
\hline \multirow[b]{2}{*}{$P$} & \multicolumn{3}{|c|}{$T_{\mathrm{m} \text {-in }}=0$} & \multicolumn{3}{|c|}{$T_{\mathrm{m} \text {-in }}=0.1$} & \multicolumn{3}{|c|}{$T_{\mathrm{m} \text {-in }}=1$} & \multicolumn{3}{|c|}{$T_{\mathrm{m} \text {-in }}=10$} \\
\hline & 0.01 & 0.1 & 1 & 0.01 & 0.1 & 1 & 0.01 & 0.1 & 1 & 0.01 & 0.1 & 1 \\
\hline$T_{\mathrm{m}-\mathrm{out}}=0$ & & & & & & & & & & & & \\
\hline$C_{\max , \mathrm{ECF}}$ & 0.35 & 1.21 & 1.57 & 1.09 & 1.45 & 1.60 & 7.88 & 3.65 & 1.88 & 83.5 & 26.0 & 4.69 \\
\hline$t_{\max , \mathrm{ECF}}$ & 4.52 & 1.91 & 1.01 & 4.45 & 1.91 & 1.02 & 4.39 & 1.90 & 1.02 & 4.18 & 1.85 & 1.02 \\
\hline$T_{\mathrm{m} \text {-out }}=0.1$ & & & & & & & & & & & & \\
\hline$C_{\max , \mathrm{ECF}}$ & 0.24 & 1.08 & 1.54 & 0.76 & 1.30 & 1.57 & 5.53 & 3.26 & 1.85 & 62.5 & 23.6 & 4.62 \\
\hline$t_{\max , \mathrm{ECF}}$ & 3.22 & 1.80 & 1.02 & 3.16 & 1.80 & 1.02 & 3.15 & 1.80 & 1.02 & 3.31 & 1.77 & 1.02 \\
\hline$T_{\mathrm{m}-\mathrm{ou}}$ & & & & & & & & & & & & \\
\hline$C_{\max , \mathrm{ECF}}$ & 0.07 & 0.55 & 1.34 & 0.23 & 0.65 & 1.37 & 1.64 & 1.65 & 1.61 & 17.6 & 12.2 & 4.04 \\
\hline$t_{\max , \mathrm{ECF}}$ & 1.65 & 1.35 & 1.01 & 1.57 & 1.35 & 1.01 & 1.55 & 1.35 & 1.01 & 1.62 & 1.37 & 1.01 \\
\hline$T_{\text {m-out }}=10$ & & & & & & & & & & & & \\
\hline$C_{\max , \mathrm{ECF}}$ & 0.01 & 0.09 & 0.59 & 0.03 & 0.11 & 0.60 & 0.19 & 0.26 & 0.70 & 1.88 & 1.87 & 1.77 \\
\hline$t_{\max . \mathrm{ECF}}$ & 1.04 & 0.98 & 0.96 & 0.99 & 0.98 & 0.96 & 0.98 & 0.98 & 0.96 & 0.98 & 0.98 & 0.96 \\
\hline
\end{tabular}

Here $C_{\text {ECF }}$ is studied in the middle of the domain. The effects of $T_{\mathrm{m} \text {-in }}$ (given in $10^{-7} \mu \mathrm{mol} \mathrm{s}^{-1}$ ), $T_{\mathrm{m} \text {-out }}\left(\right.$ given in $\left.10^{-7} \mu \mathrm{mol} \mathrm{s}^{-1}\right)$ and $P\left(\right.$ given in $10^{-7} \mathrm{~m} \mathrm{~s}^{-1}$ ) on $C_{\text {max }}$, ECF (given in $\mu \mathrm{mol} \mathrm{L}^{-1}$ ) and $t_{\text {max }}, E C F$ (given in $10^{4} \mathrm{~s}$ ) are shown. Colours are added to increase the readability of the table. Red indicates the lowest value and green indicates the highest value. The values in between are coloured according to a 20-shades red-to-green colour bar based on the log values of the data

(except for when $B_{1}{ }^{\max }$ and $k_{\text {loff }}$ are set to their reference values), $t_{\text {max }}, \mathrm{B} 1$ first increases but then decreases with higher $k_{\text {lon }}$. In all cases, except for when $k_{\text {lon }}=0.01 \mu \mathrm{mol} \mathrm{L}^{-1} \mathrm{~s}^{-1}$ and $k_{\text {loff }}=100 \cdot 10^{-2} \mathrm{~s}^{-1}, t_{\max , \mathrm{B} 1}$ greatly increases when $B_{1}{ }^{\max }=$ $500 \cdot 10^{-2} \mu \mathrm{mol} \mathrm{L}^{-1}$.

Next, as spatial differences in binding site concentrations may also occur on a small scale, we study the effect of local differences in binding site concentration within the 'reference' 3D brain unit network, with parameter values corresponding to the reference values given in Table 3, on the distribution of a drug within the network. We only assign specific binding sites to the 2x2x2 left, front and bottom units and thus set $\mathrm{B}_{\text {lmax }}=0$ for $\mathrm{x}>2 \mathrm{~d}_{\text {cap }}+4 \mathrm{r}, \mathrm{y}>2 \mathrm{~d}_{\text {cap }}+4 \mathrm{r}$ and $\mathrm{z}>2 \mathrm{~d}_{\text {cap }}+$ $4 r$. In addition, we study how different values of $B_{1}{ }^{\max }$ and $k_{\text {lon }}$ in the units containing binding sites affect local distribution within the entire 3D brain unit network. Figures 7 and 8 show the spatial distribution profiles of $C_{\mathrm{ECF}}$ and $B_{1}$, respectively. There, $C_{\mathrm{ECF}}$ is substantially smaller in the units with

Table 7 Spatial Differences in Brain Binding Site Concentrations. GR = Glucocorticoid receptor, $M R=$ Mineralocorticoid receptor, $D I R=$ Dopamine receptor DI, D2R = Dopamine receptor D2, 5-HT3AR = serotonine receptor type $3, \mathrm{CB} \mid=$ cannabinoid receptor type I. Signs are based on raw expression values given by Allen Brain Atlas, unless indicated otherwise. $--=<0.1,-=0.1-0.5, \pm=0.5-1.5,+=1.5-5,++=5-$ $10,+++=>10$. All values are based on binding site concentrations within the mouse brain. Data for 5-HT3AR are taken directly from (24), where ++ , \pm and - symbols refer to the signal intensities of 5-HT3AR linked to green fluorescent protein (GFP) in the corresponding regions of the brain

\begin{tabular}{llllll}
\hline Receptors & Cortex & Hippocampus & Pons & Cerebellum & Striatum \\
\hline CBI & ++ & ++ & + & +++ & +++ \\
DIR & \pm & \pm & - & \pm & +++ \\
D2R & \pm & - & \pm & \pm & ++ \\
GR & \pm & \pm & - & \pm & - \\
MR & - & \pm & - & - & - \\
5-HT3AR & ++ & ++ & \pm & - & + \pm \\
\hline
\end{tabular}

binding sites when either $B_{1}{ }^{\max }$ or $k_{\text {lon }}$ is high (Fig. 7). In addition, $B_{1}$ increases in the areas close to the capillaries relative to the areas in the middle of the units, furthest from the capillaries for large values of $B_{1}{ }^{\max }$ or $k_{1 \text { on }}$ (Fig. 8). When both $B_{1}{ }^{\max }$ and $k_{1 \text { on }}$ are set at their reference values, $B_{1}$ is distributed equally over space.

To conclude, changes in the kinetics of drug binding to specific binding sites most impact free and bound drug concentrations when $B_{1}{ }^{\max }$ is high. These results imply that for drugs targeting the cannabinoid type 1 ( $\mathrm{CB} 1$ ) receptor or the dopamine D1 receptor, $C_{\max , \mathrm{ECF}}$ is lower but $t_{\max , \mathrm{ECF}}$ is higher in the striatum, relative to other sites of the brain, because $\mathrm{CB} 1$ receptor concentration is highest in the striatum. This is particularly the case for drugs that strongly associate with the cannabinoid receptor (drugs that have a high value of $k_{\text {lon }}$ and a low value of $\left.k_{\text {loff }}\right)$.

\section{Combining Properties}

In this section we study the effects of BBB transport (section 3.2) and drug binding kinetics (section 3.3), combined with other drug distribution processes, including brain capillary blood flow, diffusion and brain ECF bulk flow, on brain ECF PK. To this purpose, we show the impact of combinations of parameter changes on brain EGF PK.

Figure 9 shows values of $C_{\max , \mathrm{EGF}}$ in the presence of combinations of low and high values of $\mathrm{v}_{\mathrm{blood}}, P, \mathcal{T}_{\mathrm{m} \text {-in }}$, $T_{\mathrm{m}-\text { out }}, D^{*}, \mathrm{v}_{\mathrm{ECF}}$ and in the absence or presence of binding. We now summarize the results given in Fig. 9. A change from high $P$ to low $P$ generally corresponds to a decrease in $C_{\max , \mathrm{ECF}}$. The presence of active efflux $\left(T_{\mathrm{m}-\text { out }}>0\right)$ enlarges this decrease, while a low value of $D^{*}$ or a lack of binding sites reduces this decrease. In addition, as discussed in section 3.2, in the presence of active influx a decrease in $P$ increases $C_{\max , \mathrm{ECF}}$, which is opposite to the general finding of this study. 
Table 8 Impact of Brain Binding Site Concentrations on Brain ECF PK of Unbound Drug

\begin{tabular}{r|ccc|ccc|cccc} 
& \multicolumn{3}{|c|}{$B_{1} \max =0.05$} & \multicolumn{3}{|c|}{$B_{1}^{\max }=5$} & \multicolumn{3}{c}{$B_{1}^{\max }=500$} \\
$k_{1 \text { on }}$ & 0.01 & 1 & 100 & 0.01 & 1 & 100 & 0.01 & 1 & 100 \\
\hline$k_{1 \text { off }}=0.01$ & & & & & & & & & \\
$C_{\max , \mathrm{ECF}}$ & 1.21 & 1.21 & 1.21 & 1.21 & 1.21 & 1.21 & 0.53 & 0.55 & 0.55 \\
$t_{\text {max }, \mathrm{ECF}}$ & 1.90 & 1.90 & 1.90 & 1.91 & 1.91 & 1.91 & 3.67 & 3.59 & 3.59 \\
\hline$k_{1 \text { off }}=1$ & & & & & & & & & \\
$C_{\max , \mathrm{ECF}}$ & 1.21 & 1.21 & 1.21 & 1.21 & 1.21 & 1.21 & 0.82 & 0.54 & 0.55 \\
$t_{\max , \mathrm{ECF}}$ & 1.90 & 1.90 & 1.90 & 1.91 & 1.91 & 1.91 & 2.77 & 3.64 & 3.59 \\
\hline$k_{1 \text { off }}=100$ & & & & & & & & & \\
$C_{\max , \mathrm{ECF}}$ & 1.21 & 1.21 & 1.21 & 1.21 & 1.21 & 1.21 & 1.20 & 0.82 & 0.54 \\
$t_{\max , \mathrm{ECF}}$ & 1.90 & 1.90 & 1.90 & 1.90 & 1.91 & 1.91 & 1.93 & 2.77 & 3.64
\end{tabular}

The effects of $B_{1}{ }^{\max }$ (given in $10^{-2} \mu \mathrm{mol} \mathrm{L}{ }^{-1}$ ), $k_{\text {I on }}$ (given in $\left(\mu \mathrm{mol} \mathrm{L}^{-1}\right) \mathrm{s}^{-1}$ ) and $k_{\text {l off }}$ (given in $10^{-2} \mathrm{~s}^{-1}$ ) on $C_{E C F}$ (given in $\mu$ mol L ${ }^{-1}$ ) are shown. $C_{\text {max,ECF }}$ and $t_{\max , E C F}\left(\right.$ given in $10^{4} \mathrm{~s}$ ) are shown. Colours are added to increase the readability of the table. Red indicates the lowest values of $C_{\max , E C F}$ and $t_{\max , E C F}$ and green indicates the highest values of $C_{\text {max,ECF }}$ and $t_{\max \text {,ECF }}$ The values in between are coloured according to a 20 -shades red-to-green colour bar based on the log values of the data

Active influx induces an increase in $C_{\mathrm{max}, \mathrm{ECF}}$, which is further affected by a low value of $\mathrm{v}_{\text {blood }}$ (lower increase), a high value of $\mathrm{P}$ (slightly higher or much lower increase, depending on the value of $T_{\mathrm{m} \text {-in }}$ ), the presence of active efflux (slightly lower or much lower increase, depending on the value of $\mathcal{T}_{\text {m-out }}$, a low value of $D^{*}$ (slightly higher increase) and the absence of binding sites (slightly higher increase). On the contrary, active efflux induces a decrease in $C_{\text {max,EGF, which is further affected by a low }}$ value of $P$ (larger decrease) and the presence of active influx (smaller decrease or increase, depending on the value of $T_{\mathrm{m} \text {-in }}$ ). A reduction in $D^{*}$ with respect to the reference value corresponds to a slight increase in $C_{\max , \mathrm{ECF}}$. Thereby, it counteracts the effects of decreases in $P$ and $T_{\mathrm{m} \text {-in }}$ and an increase in $T_{\mathrm{m} \text {-out }}$, which all lower $C_{\mathrm{max}, \mathrm{ECF}}$. In contrast, a decrease in $\mathrm{v}_{\mathrm{ECF}}$, does not impact $C_{\max , E C F}$. Finally, the absence of binding sites, in general, slightly increases $C_{\max , \mathrm{ECF}}$.
We have also assessed the effects of combinations of parameters on $t_{\max , \mathrm{ECF}}, C_{\max , \mathrm{B} 1}, t_{\max , \mathrm{B} 1}$, of which the data are summarized in Appendix I. In short, a low value of $P$ corresponds to a high value of $t_{\mathrm{max}, \mathrm{ECF}}$, while high values of $P$ and/or $T_{\mathrm{m} \text {-out }}$

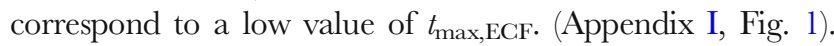
Both a decrease in $D^{*}$ and the absence of binding sites also lower $t_{\text {max,ECF. }}$.

Then, values of $C_{\max , \mathrm{B} 1}$ are mostly unaffected by parameter changes, with the exception of no binding $\left(C_{\max , \mathrm{B} 1}=0\right)$, a low value of $P$ (a slightly lower $\left.C_{\max , \mathrm{Bl}}\right)$ and a high value of $T_{\mathrm{m} \text {-out }}$ (a slightly lower $B_{\max , 1}$ ), see Appendix I, Fig. 2. Finally, the parameter combinations affect values of $t_{\max , \mathrm{B} 1}$ similarly as

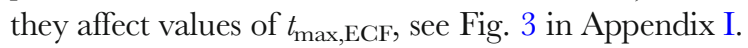

We conclude that changes in BBB transport including $\mathrm{BBB}$ permeability, $\mathrm{BBB}$ active influx and $\mathrm{BBB}$ active efflux affect brain ECF PK most. Additionally, decreases in brain ECF diffusion, which is likely impaired due to leakage of blood-derived cells into the brain ECF as

Table 9 Impact of Brain Binding Site Concentrations on Brain ECF PK of Drug Bound to Specific Binding Sites

\begin{tabular}{|c|c|c|c|c|c|c|c|c|c|}
\hline \multirow[b]{2}{*}{$k_{1 \mathrm{on}}$} & \multicolumn{3}{|c|}{$B_{1} \max =0.05$} & \multicolumn{3}{|c|}{$B_{1} \max =5$} & \multicolumn{3}{|c|}{$B_{1}^{\max }=500$} \\
\hline & 0.01 & 1 & 100 & 0.01 & 1 & 100 & 0.01 & 1 & 100 \\
\hline$k_{1 \text { off }}=0.01$ & & & & & & & & & \\
\hline$C_{\max , \mathrm{B} 1}$ & 0.05 & 0.05 & 0.05 & 4.96 & 5.00 & 5.00 & 491 & 500 & 500 \\
\hline$t_{\max , \mathrm{B} 1}$ & 2.8 & 1.89 & 1.79 & 1.96 & 1.91 & 0.66 & 3.68 & 3.56 & 3.30 \\
\hline$k_{1 \text { off }}=1$ & & & & & & & & & \\
\hline$C_{\max , \mathrm{B} 1}$ & 0.027 & 0.05 & 0.05 & 2.74 & 4.96 & 5.00 & 226 & 491 & 500 \\
\hline$t_{\max , \mathrm{B} 1}$ & 1.89 & 2.01 & 1.83 & 1.92 & 1.80 & 1.30 & 2.77 & 3.64 & 3.53 \\
\hline$k_{1 \text { off }}=100$ & & & & & & & & & \\
\hline$C_{\max , \mathrm{B} 1}$ & $6 \cdot 10^{-4}$ & 0.03 & 0.05 & 0.05 & 2.74 & 5.00 & 5.94 & 226 & 491 \\
\hline$t_{\max , \mathrm{B} 1}$ & 1.90 & 2.00 & 1.93 & 1.90 & 1.94 & 1.85 & 1.93 & 2.77 & 3.64 \\
\hline
\end{tabular}

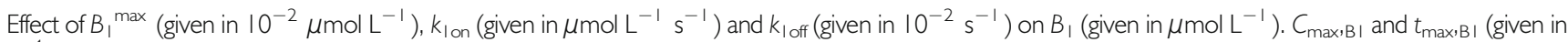
$10^{4} \mathrm{~s}$ ) are shown. Colours are added to increase the readability of the table. Red indicates the lowest value and green indicates the highest value. Red indicates the lowest values of $C_{\max , B \mid}$ and $t_{\max , B \mid}$ and green indicates the highest values of $C_{\max , B \mid}$ and $t_{\max , \mathrm{B} \mid}$. The values in between are coloured according to a 20 -shades red-to-green colour bar based on the log values of the data 
Table 10 Properties of three existing drugs targeting the brain

\begin{tabular}{|c|c|c|c|}
\hline & Morphine & Phenytoin & Methotrexate \\
\hline$P\left(\cdot 10^{-7} \mathrm{~m} \mathrm{~s}^{-1}\right)$ & 0.42 & 13 & 0.001 \\
\hline$T_{\mathrm{m} \text {-in }}\left(\cdot 10^{-7} \mu \mathrm{mol} \mathrm{s}^{-1}\right)$ & 0.384 & 0 & 0 \\
\hline$K_{\mathrm{m}-\mathrm{in}}\left(\cdot 10^{2} \mu \mathrm{mol} \mathrm{L}{ }^{-1}\right)$ & 0.000348 & 0 & 0 \\
\hline$T_{\text {m-out }}\left(\cdot 10^{-7} \mu \mathrm{mol} \mathrm{s}{ }^{-1}\right)$ & 14 & 33 & 2.1 \\
\hline$k_{\mathrm{m}-\mathrm{out}}\left(\cdot 10^{2} \mu \mathrm{mol} \mathrm{L^{-1 }}\right)$ & 0.15 & 30 & 1 \\
\hline$B_{1}{ }^{\max }\left(\cdot 10^{-2} \mu \mathrm{mol} \mathrm{L}{ }^{-1}\right)$ & 0.05 & 0.05 & 0.005 \\
\hline$k_{\text {Ion }}\left(\left(\mu \mathrm{mol} \mathrm{L}{ }^{-1}\right) \mathrm{s}^{-1}\right)$ & 0.014 & 0.025 & 37 \\
\hline$k_{\text {loff }}\left(\cdot 10^{-2} s^{-1}\right)$ & 0.23 & 50 & 0.033 \\
\hline$B_{2}{ }^{\max }\left(\cdot 10^{1} \mu \mathrm{mol} \mathrm{L}^{-1}\right)$ & 0.25 & 0.05 & 0.05 \\
\hline$k_{2 o n}\left(\cdot 10^{-2}(\mu \mathrm{mol} \mathrm{L}-1) s^{-1}\right)$ & । & 30 & । \\
\hline$k_{2 \text { off }}\left(s^{-1}\right)$ & । & । & । \\
\hline
\end{tabular}

All values are relative to the reference values in Table 3 . The influx parameters for morphine are taken from (25), the efflux parameters for morphine and methotrexate are based on $(25,28)$. Data on permeability originate from (29). Data on non-specific binding is based on data of free drug fraction in $(29,30)$.

Data on specific binding kinetics for all drugs originate from (3I)

occurs in many brain diseases (7), slightly affect brain ECF PK by increasing $C_{\text {max.ECF }}$.

\section{Examples for a Number of Existing Drugs}

We next study how brain ECF PK of 3 existing drugs with distinctive physicochemical properties (morphine, phenytoin and methrotrexate) is affected by changes in parameters that may be related to brain disease. Morphine is a drug with a relatively low $\mathrm{BBB}$ permeability that is subject to both active efflux and active influx across the BBB (25). Phenytoin is a drug that easily crosses the $\mathrm{BBB}$ via passive transport and is not subject to significant active transport and has high nonspecific binding $(26,27)$. Finally, methotrexate is a drug with a very low BBB permeability that is subject to active efflux (28). The drug-specific parameter values for morphine, phenytoin and methotrexate are summarized in Table 10, while all other parameters are given in Table 3 . The values of $B_{2 \max }, k_{2 \text { on }}$ and $k_{2 \text { off }}($ Table 10) are, due to a lack of experimental data on non-specific binding kinetics, based on the brain 'fraction unbound' ( $\left.\frac{\text { Free drug in brain }}{\text { Total drug in brain }}\right)$ reported in literature $(29,30): \quad$ the values of $B_{2 \max }, k_{2 \text { on }}$ and $k_{2 \text { off }}$ have been tuned until, in the presence of a constant value of $C_{\mathrm{p}}$, the 3D brain unit model showed a value of the fraction unbound (calculated as $\mathrm{C}_{\mathrm{ECF}} /\left(\mathrm{C}_{\mathrm{ECF}}+\mathrm{B}_{1}+\mathrm{B}_{2}\right)$ that was identical to the value reported in literature. Figure 10 shows morphine, phenytoin and methotrexate brain ECF PK under reference conditions with all drug-specific parameter values as in Table 10 (Fig. 10, black lines) and with parameters that reflect changes in BBB transport (Fig. 10, left) or binding site concentrations (Fig. 10, right). To investigate the relation between drug within the blood plasma (measurable) and within the brain ECF (often not measurable), blood plasma PK (calculated with parameters as in Table 3) is taken the same for all three drugs. We observe from Fig. 10 (left) that morphine brain ECF PK is highly affected by several changes in BBB transport. An increase in BBB permeability (high $\mathrm{P}$ ) only slightly increases $C_{\max \text { ECF }}$, which reflects the fact that
Fig. 5 The effect of changes in passive BBB permeability and active BBB influx on unbound drug concentrations within the brain ECF. The BBB permeability, $P$ is set at low $\left(0.01 \cdot 10^{-7} \mathrm{~m} \mathrm{~s}^{-1}\right)$, at its reference value $\left(0.1 \cdot 10^{-7} \mathrm{~m} \mathrm{~s}^{-1}\right)$ or high $\left(1 \cdot 10^{-7} \mathrm{~m} \mathrm{~s}^{-1}\right)$. The active BBB influx transporter velocity, $T_{\mathrm{m} \text {-in }}$ is set at $0.1 \cdot 10^{-7} \mu \mathrm{mol} \mathrm{s}^{-1}$ (low), $1 \cdot 10^{-7} \mu \mathrm{mol} \mathrm{s}^{-1}$ (reference value) or $10 \cdot 10^{-7} \mu \mathrm{mol} \mathrm{s}{ }^{-1}$ (high). Darker shades of blue correspond to higher concentrations of unbound drug within the brain ECF. Distribution profiles are shown at $t=50 \mathrm{~s}$.

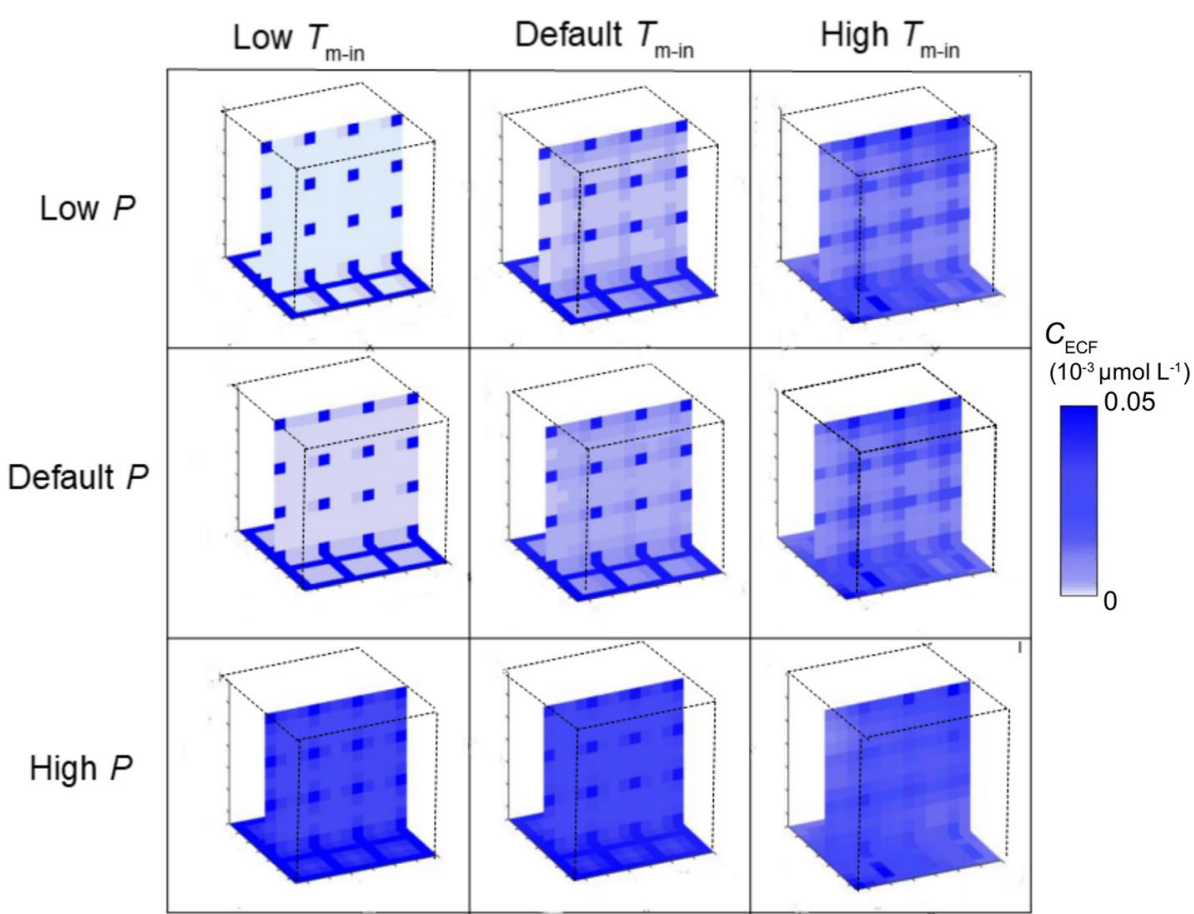


Fig. 6 The effect of changes in passive BBB permeability and active efflux on unbound drug concentrations within the brain ECF. The BBB permeability, $P$ is set at low $\left(0.01 \cdot 10^{-7} \mathrm{~m} \mathrm{~s}^{-1}\right)$, at its reference value $\left(1 \cdot 10^{-7} \mathrm{~m} \mathrm{~s}^{-1}\right)$ or high $\left(100 \cdot 10^{-7} \mathrm{~m} \mathrm{~s}^{-1}\right)$. The active BBB efflux transporter velocity, $T_{\mathrm{m} \text {-out }}$ is set at $0.1 \cdot 10^{-7} \mu \mathrm{mol} \mathrm{s}^{-1}$ (low), $1 \cdot 10^{-7} \mu \mathrm{mol} \mathrm{s}^{-1}$ (reference value) or $10 \cdot 10^{-7} \mu \mathrm{mol} \mathrm{s}{ }^{-1}$ (high). Higher intensities of blue correspond to higher concentrations of unbound drug within the brain ECF.

Distribution profiles are shown at $\mathrm{t}=50 \mathrm{~s}$

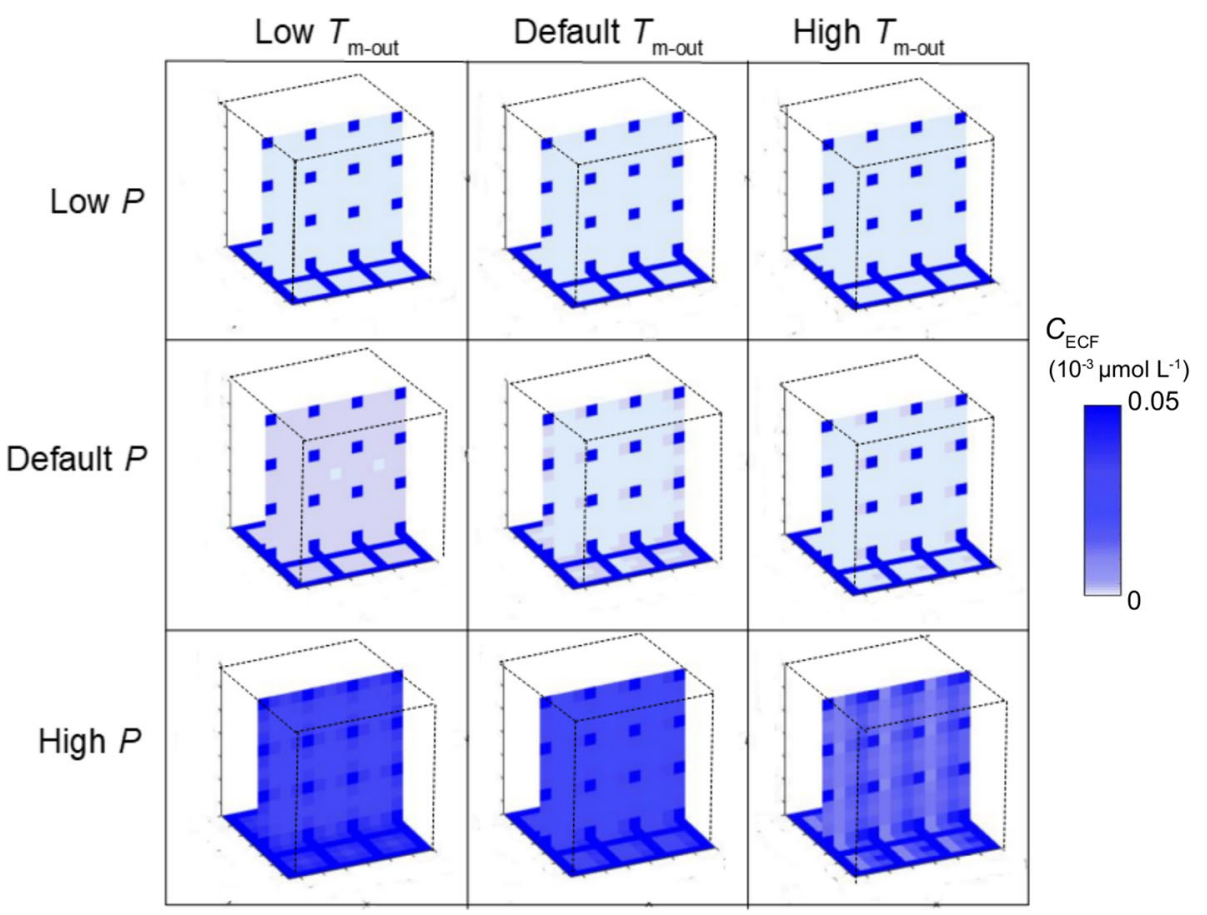

morphine brain ECF PK is mostly regulated by BBB active influx and active efflux. Inhibition of influx $\left(T_{\mathrm{m}-\text { in }}=0\right)$ leads to a lower $C_{\text {max,ECF }}$ and a faster decrease of $C_{\text {max,EGF }}$ In contrast, inhibition of efflux increases $C_{\text {max,ECF}}$, but does not change the shape of the brain ECF concentration-time profile of morphine. An increase in efflux lowers $C_{\text {max } \text { ECF, }}$ but, again, does not change the shape of the brain ECF PK of morphine. Inhibition of both influx and efflux results in a higher $C_{\max , \mathrm{ECF}}$, but with a concentration-time profile that is similar in shape to the concentration- time profile when only influx is inhibited. While morphine brain EGF PK is greatly affected by changes in BBB transport, it is unaffected by changes in concentrations of both specific and nonspecific binding sites (Fig. 10, right). In contrast to morphine concentrations, phenytoin concentrations are hardly affected by increases in $P$, as, by default, phenytoin easily crosses
Fig. 7 The effect of changes in specific binding site density and association rate constant on unbound drug concentrations within the brain ECF. The target concentration, $B_{1}{ }^{\max }$ is set at $0.01 \cdot 10^{-2} \mu \mathrm{mol} \mathrm{L}-1$ (low), $1 \cdot 10^{-2} \mu \mathrm{mol} \mathrm{L}{ }^{-1}$ (reference value) or $100 \cdot 10^{-2} \mu \mathrm{mol} \mathrm{L}{ }^{-1}$. The association rate constant of drug with its target, $k_{\text {Ion }}$ is set at $0.01 \mu \mathrm{mol} \mathrm{L}^{-1} \mathrm{~s}^{-1}$ (low), I $\mu \mathrm{mol} \mathrm{L} \mathrm{L}^{-1} \mathrm{~s}^{-1}$ (reference value) or $100 \mu \mathrm{mol} \mathrm{L} \mathrm{L}^{-1} \mathrm{~s}^{-1}$ (high). Higher intensities of blue correspond to higher concentrations of unbound drug within the brain ECF.

Distribution profiles are shown at $\mathrm{t}=100$

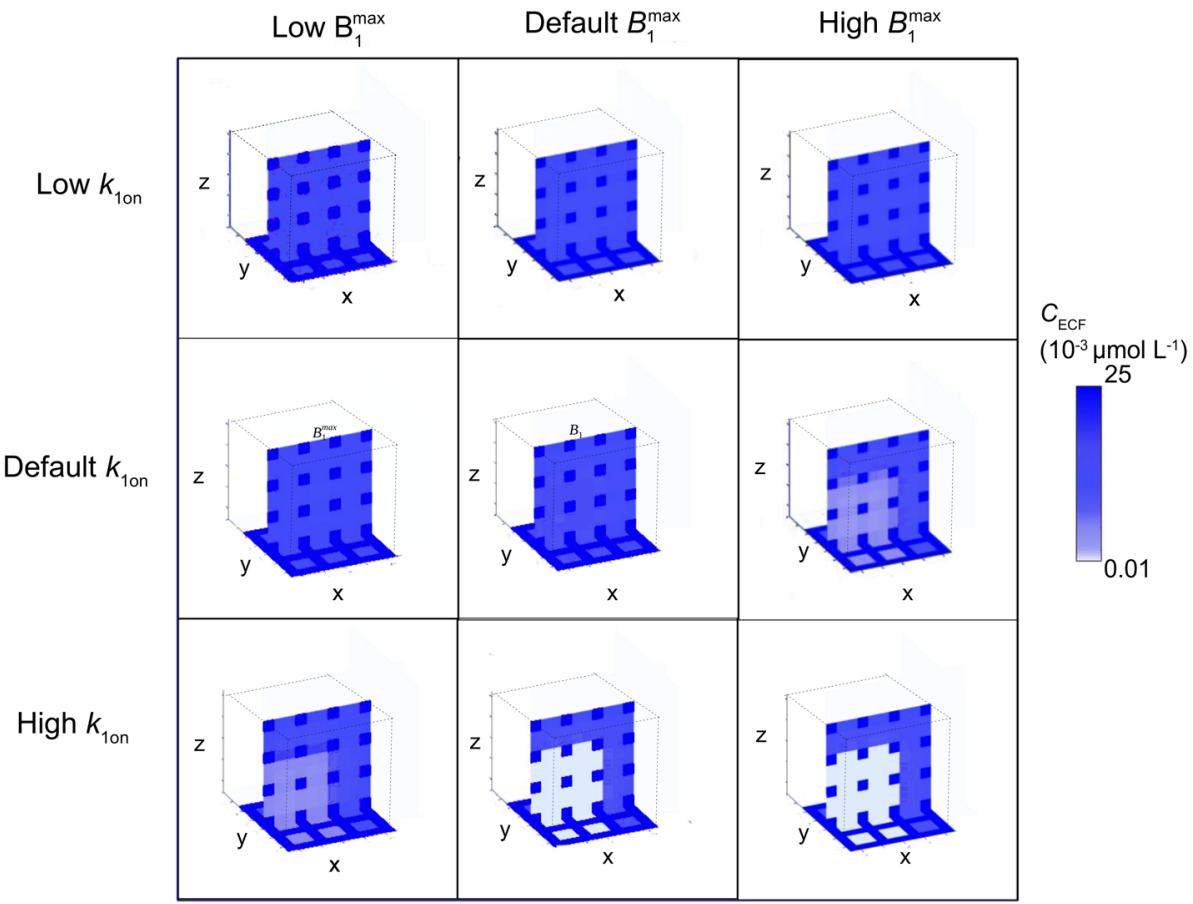


Fig. 8 The effect of changes in specific binding site density and association rate constant on concentrations of target-bound drug within the brain ECF. The total target concentration, $B_{1}{ }^{\text {max }}$ is set at $0.01 \cdot 10^{-2} \mu \mathrm{mol} \mathrm{L}{ }^{-1}$ (low), $1 \cdot 10^{-2} \mu \mathrm{mol} \mathrm{L} \mathrm{L}^{-1}$ (reference value) or $100 \cdot 10^{-2} \mu \mathrm{mol} \mathrm{L}{ }^{-1}$ (high). The association rate constant of drug with its target, $k_{\text {lon }}$ is set at $0.01 \mu \mathrm{mol} \mathrm{L}^{-1} \mathrm{~s}^{-1}$ (low), I $\mu \mathrm{mol} \mathrm{L}^{-1} \mathrm{~s}^{-1}$ (reference value) or $100 \mu \mathrm{mol} \mathrm{L}^{-1} \mathrm{~s}^{-1}$ (high). Higher intensities of green correspond to higher concentrations of drug bounds to targets facing the brain ECF. White corresponds to a concentration of bound drug that equals zero, like in the blood plasma of the brain capillaries, or, in case of strong binding to a high concentration of specific binding sites (bottom right) in the middle of the units. Distribution profiles are shown at $\mathrm{t}=100$

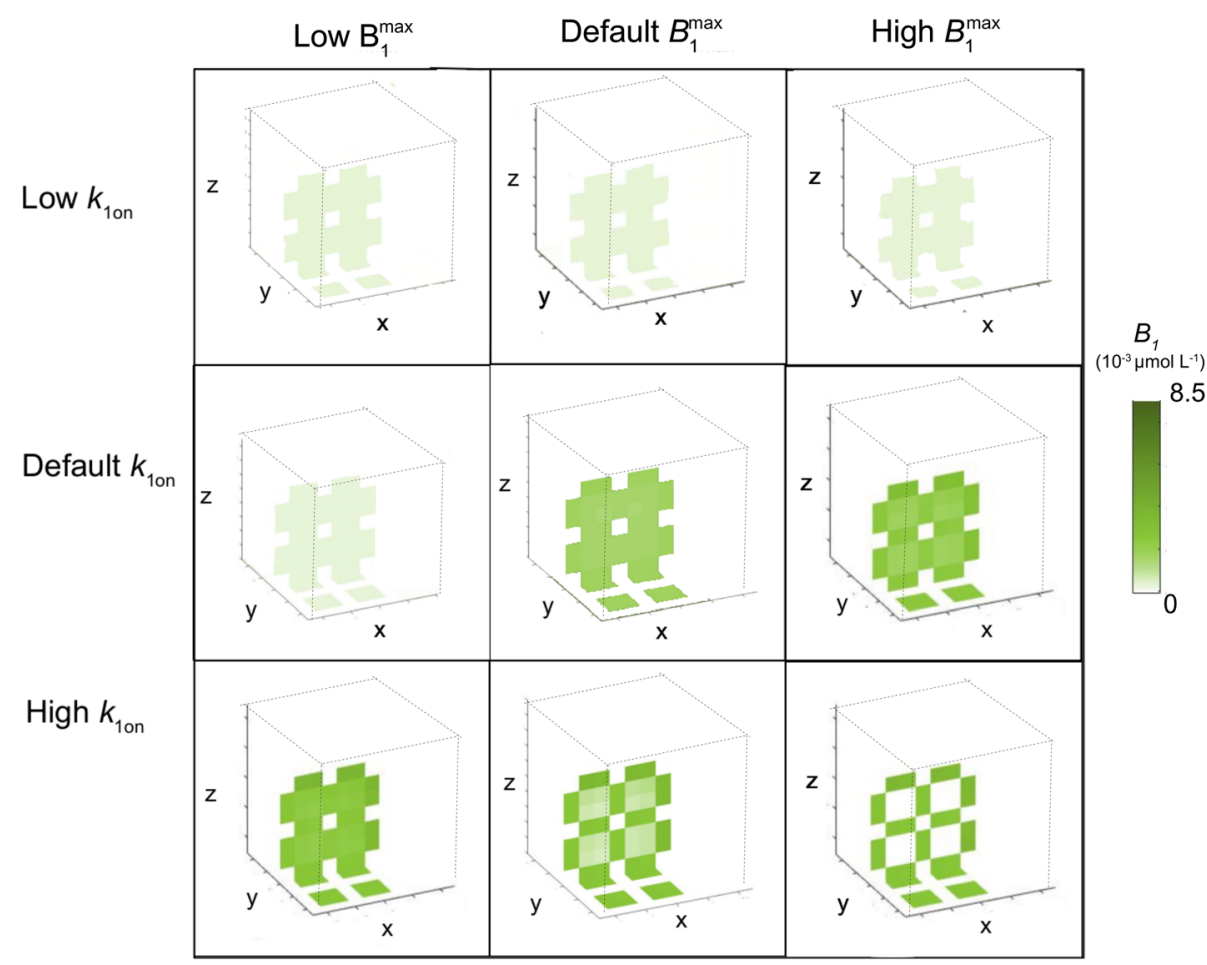

the BBB (Fig. 10). In addition, while phenytoin brain ECF $\mathrm{PK}$ is unaffected by decreases in concentrations of both specific and non-specific binding sites, phenytoin brain ECF PK is affected by an increase in $B_{2}{ }^{\text {max }}$ (Fig. 10): an increase in $B_{2}{ }^{\text {max }}$ slightly decreases $C_{\max , \text { ECF}}$, while it increases $t_{\max , \mathrm{EGF}}$ (Fig. 10).
Finally, methotrexate concentrations within the brain $\mathrm{ECF}$ are very low due to its low BBB permeability and high efflux. Therefore, both an increase in $P$ (Fig. 10, down left, green line) and an inhibition of efflux (Fig. 10, down left, red line) lead to a higher value of $C_{\text {max,ECF. }}$ On the other hand, a high value of $T_{\text {m-out }}$ results in a lower

\begin{tabular}{|c|c|c|c|c|c|c|c|c|c|c|c|c|c|c|c|}
\hline & \multicolumn{2}{|l|}{$V_{\text {blood }}$} & \multicolumn{2}{|l|}{$P$} & \multicolumn{2}{|l|}{$T_{\min }$} & \multicolumn{2}{|l|}{$T_{\text {m,out }}$} & \multicolumn{2}{|l|}{$D^{*}$} & \multicolumn{2}{|l|}{$V_{E C F}$} & \multicolumn{2}{|c|}{ Binding } \\
\hline & & Low & Default & Low & High & Low & High & Low & High & Low & Default & Low & Default & None & Default \\
\hline \multirow[t]{2}{*}{$V_{\text {blood }}$} & & & & 0.35 & 1.57 & 1.45 & 24.8 & 1.08 & 0.09 & 1.33 & 1.21 & 1.21 & 1.21 & 1.34 & 1.21 \\
\hline & Default & & & 0.35 & 1.57 & 1.45 & 26.0 & 1.08 & 0.09 & 1.33 & 1.21 & 1.21 & 1.21 & 1.34 & 1.21 \\
\hline \multirow[t]{2}{*}{$P$} & Low & 0.35 & 0.35 & & & 1.09 & 83.5 & 0.24 & 0.009 & 0.46 & 0.35 & 0.34 & 0.35 & 0.49 & 0.35 \\
\hline & High & 1.57 & 1.57 & & & 1.6 & 4.7 & 1.54 & 0.59 & 1.57 & 1.57 & 1.57 & 1.57 & 1.57 & 1.57 \\
\hline \multirow[t]{2}{*}{$T_{\min }$} & Low & 1.45 & 1.45 & 1.09 & 1.6 & & & 1.30 & 0.11 & 1.64 & 1.45 & 1.44 & 1.45 & 1.61 & 1.45 \\
\hline & High & 24.9 & 26.0 & 83.5 & 4.7 & & & 23.6 & 1.87 & 30.0 & 26.0 & 26.0 & 26.0 & 28.1 & 26.0 \\
\hline \multirow[t]{2}{*}{$T_{\text {m,out }}$} & Low & 1.08 & 1.08 & 0.24 & 1.54 & 1.30 & 23.6 & & & 1.15 & 1.08 & 1.08 & 1.08 & 1.18 & 1.08 \\
\hline & High & 0.09 & 0.09 & 0.009 & 0.59 & 0.11 & 1.87 & & & - & 0.09 & 0.09 & 0.09 & 0.09 & 0.09 \\
\hline \multirow[t]{2}{*}{$D^{*}$} & Low & 1.33 & 1.33 & 0.46 & 1.57 & 1.64 & 30.0 & 1.15 & - & & & 1.21 & 1.21 & 1.43 & 1.21 \\
\hline & Default & 1.21 & 1.21 & 0.35 & 1.57 & 1.45 & 26.0 & 1.08 & 0.09 & & & 1.21 & 1.21 & 1.34 & 1.21 \\
\hline \multirow[t]{2}{*}{$v_{\text {ECF }}$} & Low & 1.21 & 1.21 & 0.34 & 1.57 & 1.45 & 25.7 & 1.08 & 0.09 & 1.21 & 1.21 & & & 1.34 & 1.21 \\
\hline & Default & 1.21 & 1.21 & 0.35 & 1.57 & 1.45 & 26.0 & 1.08 & 0.09 & 1.21 & 1.21 & & & 1.34 & 1.21 \\
\hline \multirow[t]{2}{*}{ Binding } & None & 1.34 & 1.34 & 0.49 & 1.57 & 1.61 & 28.1 & 1.18 & 0.09 & 1.43 & 1.34 & 1.34 & 1.34 & & \\
\hline & Default & 1.21 & 1.21 & 0.35 & 1.57 & 1.45 & 26.0 & 1.08 & 0.09 & 1.21 & 1.21 & 1.21 & 1.21 & & \\
\hline
\end{tabular}

Fig. 9 Integration of properties. The impact of combinations of parameters on $C_{\text {max,ECF }}$ is shown. Reference parameter values are as in Table 3. Low $v_{\text {blood }}=$ $0.5 \cdot 10^{-4} \mathrm{~m} \mathrm{~s}^{-1}$, low $P=0.01 \cdot 10^{-7} \mathrm{~m} \mathrm{~s}^{-1}$, high $P=1 \cdot 10^{-7} \mathrm{~m} \mathrm{~s}^{-1}$, low $T_{\mathrm{m} \text {-in }}=0.1 \cdot 10^{-7} \mu \mathrm{mol} \mathrm{L} \mathrm{s}^{-1}$, high $T_{\mathrm{m}-\text { in }}=10 \cdot 10^{-7} \mu \mathrm{mol} \mathrm{L} \mathrm{L}^{-1} \mathrm{~s}^{-1}$, low $T_{\mathrm{m}-\text { out }}=$ $0.1 \cdot 10^{-7} \mu \mathrm{mol} \mathrm{L} \mathrm{s}^{-1} \mathrm{~s}^{-1}$, high $T_{\mathrm{m} \text {-out }}=10 \cdot 10^{-7} \mu \mathrm{mol} \mathrm{L}^{-1} \mathrm{~s}^{-1}$, low $D^{*}=0.05 \cdot 10^{-10} \mathrm{~m}^{2} \mathrm{~s}^{-1}$, low $v_{\mathrm{ECF}}=0.05 \cdot 10^{-10} \mathrm{~m} \mathrm{~s} \mathrm{~s}^{-1}$. Binding includes the concentrations of both specific and non-specific binding sites, i.e. when binding is none, $B_{1}{ }^{\max }=0$ and $B_{2}{ }^{\max }=0$. For clarity, the table is symmetric, such that both the effect of parameter $A$ on parameter $B$ and the effect of parameter $B$ on parameter $A$ can be easily assessed. Colours are added to increase the readability of the table. Red indicates the lowest values of $C_{\text {max,ECF }}$ and $t_{\text {max,ECF }}$ and green indicates the highest values of $C_{\text {max,ECF }}$ and $t_{\text {max,ECF }}$ The values in between are coloured according to a 20-shades red-to-green colour bar based on the log values of the data. 
Changes in BBB functionality Morphine

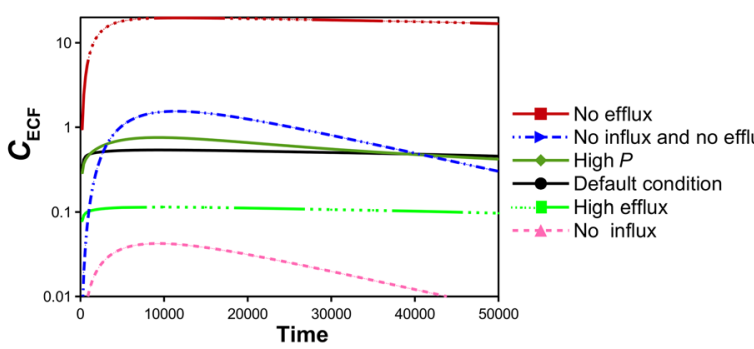

Phenytoin

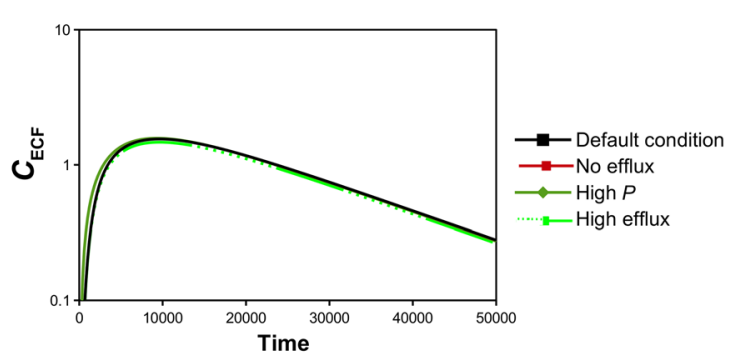

Methotrexate

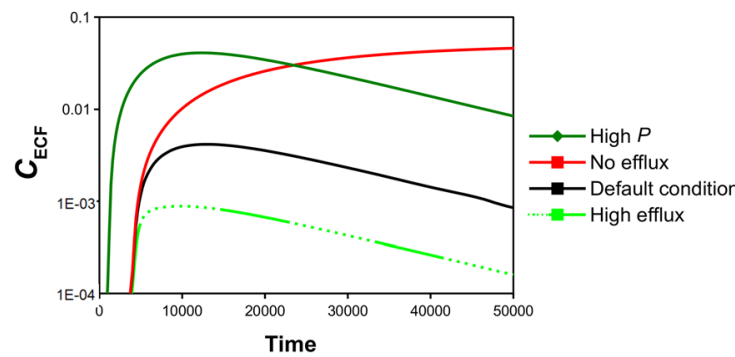

Changes in binding site

concentrations
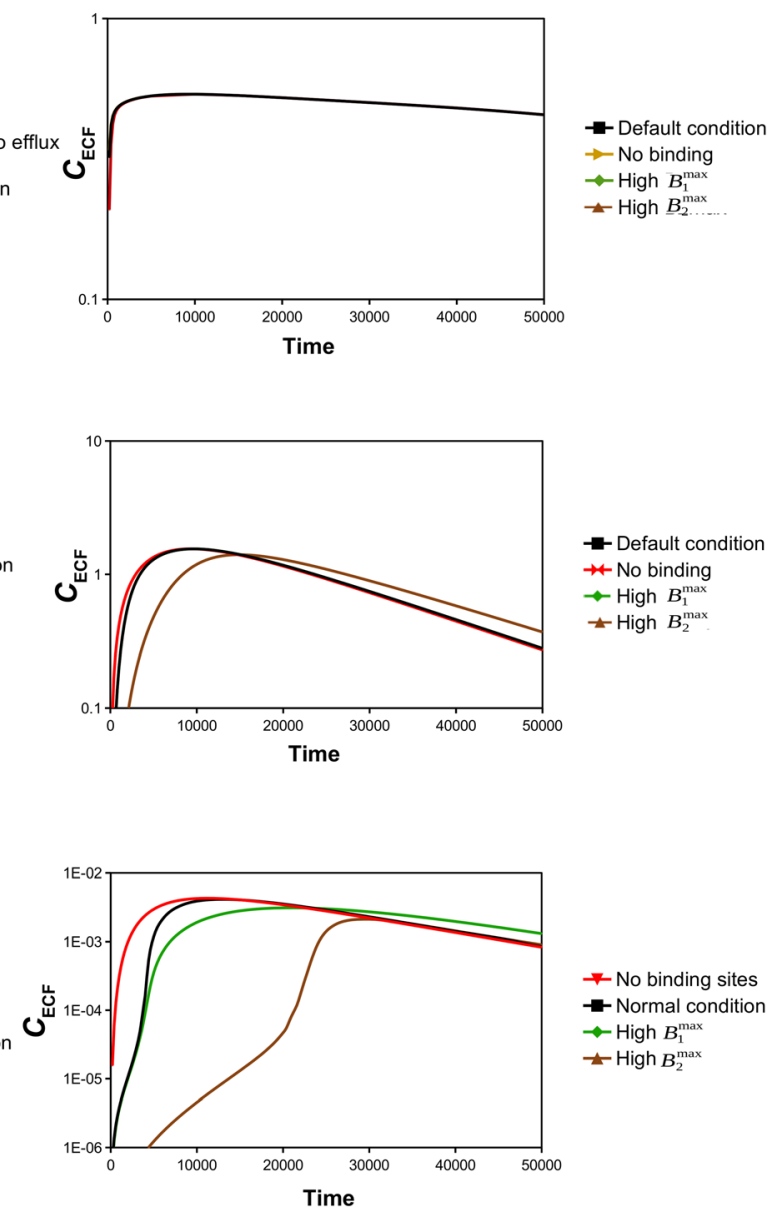

Fig. 10 Brain ECF PK of existing drugs under health and disease conditions. Brain ECF PK of morphine (top), phenytoin (middle) and methotrexate (low) is shown under reference conditions (in black) and under conditions of changes in BBB permeability and binding properties (in green and red). Left: Effect of changes in BBB transport on brain ECF PK. The BBB permeability is increased (green), or decreased (red). For compounds with active influx and/or efflux, the BBB permeability is also increased (green) or decreased (green). Right: Effect of changes in binding site concentrations on brain ECF PK. Either the concentration of specific or non-specific binding sites is zero (no binding, red) or high (green for $B_{1}{ }^{\max }$, brown for $B_{2}^{\text {max }}$ ).

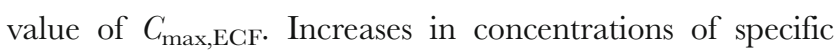
and, particularly, non-specific binding sites correspond to great increases in $t_{\max , \mathrm{ECF}}$ and only slight decreases in $C_{\text {max,ECF }}$ (Fig. 10, down right). In similar fashion, the absence of both specific and non-specific binding sites

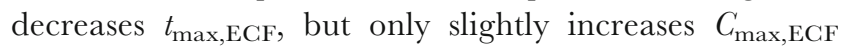
(Fig. 10, down right). In conclusion, our simulations predict that morphine $\mathrm{PK}$ is greatly affected by changes in $\mathrm{BBB}$ active influx and active efflux and thus, morphine PK likely changes in diseases like Alzheimer's, ALS, epilepsy and brain cancer. Finally, for methotrexate the model predicts that an increase in BBB permeability or a disruption of BBB active efflux, like may occur in stroke, increases $C_{\mathrm{ECF}}$, while an increase in $\mathrm{BBB}$ active efflux, like may occur in ALS, epilepsy and brain cancer, decreases $C_{\mathrm{ECF}}$. Both phenytoin and methotrexate are affected by high concentrations of non-specific binding sites, which may differ within the brain.

\section{DISCUSSION}

We have developed a mathematical model that describes the spatial distribution of a drug within a 3D brain unit network. The 3D brain unit network model is an extension of our earlier 3D brain unit model (submitted to PLOS Computational Biology). It enables the study of spatial concentration differences at two levels:

1) The entire 3D brain unit network in health and disease conditions. Disease conditions are reected by differences in parameters that may arise due to differences in brain capillary density (section 3.1), BBB transport (for example due to local 
disease, section 3.2) or local specific binding site density (section $3.3)$.

2) Local differences in parameters between units within the network, see Figs 8 and 9.

In our studies we have focused on the effect of brain capillary density, BBB transport and drug binding kinetics on brain ECF PK. First, in section 3.1, we have studied the effect of brain capillary density on brain ECF PK. The brain capillary density is often related to other properties, like the spatial organization of the blood vessels, changes in brain capillary diameter, or local obstructions. For simplicity, we have chosen to base the brain capillary density only on the distance between the capillaries, $d_{\text {cap }}$. We have found a positive correlation between brain capillary density and drug concentrations within the brain ECF, for low values of BBB permeability (Fig. 5). No significant affect of brain capillary density was observed for high values of BBB permeability. The relationship between capillary density and drug uptake was investigated in an experimental study on drug distribution within the murine brain (32). There, a positive correlation between capillary density and drug uptake was found within the brain of mice lacking the active transporter P-glycoprotein for three drugs with different values of BBB permeability. Unlike in our study, brain capillary density did affect drug uptake into the brain ECF with higher values of BBB permeability. However, the study was performed with the brain perfusion technique and focused on initial drug uptake into the brain, while in our model we also take the processes after drug uptake into account, i.e. drug distribution within and elimination from the brain. It is likely that in the presence of a high permeability, diffusion contributes to a quick equilibration of drug within the blood plasma and the brain ECF, but this requires further investigation.

Changes in parameters related to BBB transport, as may occur in disease conditions, affect brain EGF PK, including $C_{\max , \mathrm{ECF}}, t_{\max , \mathrm{ECF}}$, and the spatial distribution of a drug, within the 3D brain unit network (Section 3.2). There, BBB active transport depends on the permeability of the BBB to the drug and the impact of both active influx and active efflux decreases with a higher BBB permeability. Indeed, mostly drugs that have difficulties crossing the BBB (due to high polarity and high molecular weight) are shown to be significantly impacted by active efflux (33).

In section 3.3 we have shown that specific binding site density affects brain ECF PK of unbound drug and drug bound to specific binding sites within the 3D brain unit network. Moreover, we have shown how local differences in specific binding site concentration affect the distribution of $C_{\mathrm{ECF}}$ within the $3 \mathrm{D}$ brain unit network. The distribution profiles of $C_{\mathrm{ECF}}$ and $B_{1}$ are particularly affected by $B_{1}{ }^{\text {max }}$, as is shown in Tables 7 and 8. In addition, increasing $k_{1 \text { on }}$ has similar effects on $C_{\text {ECF }}$ and $B_{1}$ as decreasing $k_{\text {loff. }}$ This is in line with recent studies stating that target association and dissociation are equally important $(34,35)$.

Finally, in section 3.4 , we have shown how a combination of properties (for example, the combination of an increased BBB permeability and a decreased diffusion, as occurs in many brain diseases (7)) impacts $C_{\text {ECF }}$. We situated how different BBB and brain distribution parameter values (due to local disease and location) a_ect the concentration-time profiles of 3 existing drugs. We find that morphine brain ECF PK is mainly determined by the balance between active influx and active efflux, as has been shown before (25). Therefore, the shape of the concentration-time profile greatly changes when $\mathrm{BBB}$ influx or efflux is affected, but not when BBB permeability is increased (Fig. 10). Phenytoin brain ECF PK within the 3D brain unit network is hardly affected by BBB transport. This is partly in line with experimental findings that epileptic-seizure-induced increases in BBB transport do not increase, but, interestingly, rather decrease unbound phenytoin concentrations in rat brain ECF (36). This decrease is possibly caused by enhanced extracellular protein binding related to seizure induction $(36,37)$.

Methotrexate concentrations are affected by both changes in BBB transport and high concentrations of binding sites (Fig. 10). In addition, experiments have shown that methrotexate concentrations are affected by intra-extracellular exchange: upon entering cells, methotrexate is converted into polyglutamate methotrexate by metabolic enzymes (38). This leads to 'trapping' of methotrexate in the cells, thereby greatly affecting the concentrations of methotrexate in the brain ECF. In our model, however, we do not distinguish between intracellular and extracellular compartments and therefore we have not taken intracellular trapping of methotrexate into account. Our future goal is to distinguish between intracellular and extracellular compartments and binding sites.

The focus of our model is on drug distribution within the brain, after transport of drug into the brain from the brain vasculature. Therefore, the $3 \mathrm{D}$ brain unit network model represents a small region of interest, where the brain capillaries, which are the major site of exchange between the blood and the brain, surround the brain ECF. In the future, one or multiple 3D brain unit networks can be implemented in a large-scale 3D model of the brain, that describes drug transport into and within larger areas of the brain. Due to the large scale of such a model, it is feasible that 3D brain unit 
networks only describe a small region of interest, which is generally the area the drug is targeting, like the area of local disease or the area where most drug targets are located. The other areas should then be described in less detail, i.e. by larger units describing regions where differences are non-existent or negligible.

We have shown that our model is suitable for the study of drug distribution within a small part of the brain. The parameters inherent to this specific area of interest can be easily put into our model to study drug distribution within this area. In addition, data on particular existing drugs can be implemented by using parameters inherent to this drug (see Table 10). As such, the 3D brain unit network model enables the study of the distribution of specific drugs within a specific area of interest in the brain. In addition, it enables the study on how spatial distribution is affected by changes in parameters, as induced by differences in location or by local disease. In summary, the 3D brain unit network model provides an excellent starting point to study the distribution of a drug within the brain and assess the effect of spatial differences within the brain on spatial distribution of a drug within the brain.

\section{COMPLIANCE WITH ETHICAL STANDARDS}

Conflict of Interest The authors declare that they have no conict of interest.

Open Access This article is licensed under a Creative Commons Attribution 4.0 International License, which permits use, sharing, adaptation, distribution and reproduction in any medium or format, as long as you give appropriate credit to the original author(s) and the source, provide a link to the Creative Commons licence, and indicate if changes were made. The images or other third party material in this article are included in the article's Creative Commons licence, unless indicated otherwise in a credit line to the material. If material is not included in the article's Creative Commons licence and your intended use is not permitted by statutory regulation or exceeds the permitted use, you will need to obtain permission directly from the copyright holder. To view a copy of this licence, visit http://creativecommons.org/licenses/by/4.0/.

\section{REFERENCES}

1. Hammarlund-Udenaes M, Paalzow LK, de Lange ECM. Drug equilibration across the blood-brain barrier-pharmacokinetic considerations based on the microdialysis method. Pharm Res. 1997;14(2):128-34.
2. Vendel E, Rottschäfer V, de Lange ECM. The need for mathematical modelling of spatial drug distribution within the brain. Fluids and Barriers of the CNS. 2019;16(1):12.

3. Drouin-Ouellet J, Sawiak SJ, Cisbani G, Lagacé M, Kuan WL, Saint-Pierre M, et al. Cerebrovascular and blood-brain barrier impairments in Huntington's disease: Potential implications for its pathophysiology. Ann Neurol. 2015;78:160-77.

4. Lin CY, Hsu YH, Lin MH, Yang TH, Chen HM, Chen YG, et al. Neurovascular ab normalities in humans and mice with Huntington's disease. Exp Neurol. 2013;250:20-30.

5. Hinds JW, McNelly NA. Capillaries in aging rat olfactory bulb: A quantitative light and electron microscopic analysis. Neurobiol Aging. 1982;3:197-207.

6. Wilkinson JH, Hopewell JW, Reinhold HS. A quantitative study of age-related changes in the vascular architecture of the rat cerebral cortex. Neuropathol Appl Neurobiol. 1981;7:451-62.

7. Sweeney MD, Sagare AP, Zlokovic BV. Blood-brain barrier breakdown in Alzheimer disease and other neurodegenerative disorders. Nat Rev Neurol. 2018;14(3):133.

8. Mahfouz A, Lelieveldt BP, Grefhorst A, Van Weert LT, Mol IM, Sips HC, et al. Genome wide coexpression of steroid receptors in the mouse brain: Identifying signaling pathways and functionally coordinated regions. Proc Natl Acad Sci. 2016;113(10):2738-43.

9. Vendel E, Rottschäfer V, de Lange ECM. Improving the prediction of local brain distribution profiles with a new mathematical model. Bulletin for Mathematical Biology, Special Issue on Mathematics to Support Drug Discovery and Development. 2018:1-31.

10. Schiesser WE, Griffiths GW. A compendium of partial di_erential equation models: method of lines analysis with Matlab. Cambridge: Cambridge University Press; 2009.

11. van Assema MED, Lubberink M, Bauer M, van der Flier WM, Schuit RC, Wind Horst AD, et al. Blood-Brain Barrier Pglycoprotein function in Alzheimer's disease. Brain. 2012;135(1): 181-9.

12. Deo AK, Borson S, Link JM, Domino K, Eary JF, Ke B, et al. Activity of P Glycoprotein, a _-amyloid transporter at the bloodbrain barrier, is compromised in patients with mild Alzheimer disease. J Nucl Med. 2014;55(7):1106-11.

13. Garbuzova-Davis S, Hernandez-Ontiveros DG, Rodrigues MC, Haller E, Frisina-Deyo A, Mirtyl S, et al. Impaired blood-brain/ spinal cord barrier in ALS patients. Brain Res. 2012;1469:114-28.

14. Winkler EA, Sengillo JD, Sullivan JS, Henkel JS, Appel SH, Zlokovic BV. Blood-spinal cord barrier breakdown and pericyte reductions in amyotrophic lateral sclerosis. Acta Neuropathol. 2013;125(1):111-20.

15. Pekcek A, Unkrüer B, Stein V, BankstahlJP, Soerensen J, Tipold A, et al. Over expression of P-glycoprotein in the canine brain following spontaneous status epilepticus. Epilepsy Res. 2009;83(2-3):144 51.

16. KirkJ, PlumbJ, Mirakhur M, McQuaid S. Tight junctional abnormality in multiple sclerosis white matter a_ects all calibres of vessel and is associated with blood-brain barrier leakage and active demyelination. J Pathol. 2003;201:319-27.

17. Kortekaas R, Leenders KL, van Oostrom JCH, Vaalburg W, Bart $\mathrm{J}$, Willemsen ATM, et al. Blood-brain barrier dysfunction in parkinsonian midbrain in vivo. Ann Neurol. 2005;57:176-9.

18. Gray MT, Woulfe JM. Striatal blood-brain barrier permeability in Parkinson's disease. J Cereb Blood Flow Metab. 2015;35(5):74750.

19. Pienaar IS, Lee CH, Elson JL, McGuinness L, Gentleman SM, Kalaria RN, et al. Deep brain stimulation associates with improved microvascular integrity in the subthalamic nucleus in Parkinson's disease. Neurobiol Dis. 2015;74:392-405.

20. Abdullahi W, Tripathi D, Ronaldson PT. Blood-brain barrier dysfunction in ischemic stroke: targeting tight junctions and 
transporters for vascular protection. Am J Physiol Cell Physiol. 2018;315(3):C343-56.

21. Jiang X, Andjelkovic AV, Zhu L, Yang T, Bennett MVL, Chen J, et al. Blood-brain barrier dysfunction and recovery after ischemic stroke. Prog Neurobiol. 2018;163-164:144-71.

22. Cordon-Cardo C, O'Brien JP, Boccia J, Casals D, Bertino JR, Melamed MR. Expression of the multidrug resistance gene product (P-glycoprotein) in human normal and tumor tissues. J Histochem Cytochem. 1990;38(9):1277-87.

23. Qosa H, Miller DS, Pasinelli P, Trotti D. Regulation of ABC e_ux transporters at blood-brain barrier in health and neurological disorders. Brain Res. 2015;1628:298-316.

24. Koyama Y, Kondo M, Shimada S. Building a 5-HT3A receptor expression map in the mouse brain. Sci Rep. 2017;7:42884.

25. Groenendaal D, Freijer J, De Mik D, Bouw M, Danhof M, de Lange E. Population pharmacokinetic modelling of non-linear brain distribution of morphine: inuence of active saturable inux and P-glycoprotein mediated efflux. Br J Pharmacol. 2007;151(5):701-12.

26. Yamamoto Y, Välitalo PA, van den Berg DJ, Hartman R, van den Brink W, Wong YC, et al. A generic multi-compartmental CNS distribution model structure for 9 drugs allows prediction of human brain target site concentrations. Pharm Res. 2016:1-19.

27. Yamamoto Y, Välitalo PA, Huntjens DR, Proost JH, Vermeulen A, Krauwinkel W, et al. Predicting drug concentration-time profiles in multiple CNS compartments using a comprehensive physiologically-based pharmacokinetic model. CPT Pharmacometrics Syst Pharmacol. 2017;6(11):765-77.

28. Westerhout J, van den Berg DJ, Hartman R, Danhof M, de Lange ECM. Prediction of methotrexate GNS distribution in di erent species - Inuence of disease conditions. Eur J Pharm Sci. 2014;57: $11-24$.

29. Yamamoto Y, Välitalo PA, Wong YC, Huntjes DR, Proost JH, Vermeulen A, et al. Prediction of human CNS pharmacokinetics using a physiologically-based pharmacokinetic modeling approach. Eur J Pharm Sci. 2018;112:168-79.

30. Kalvas JC, Maurer TS, Pollack GM. Use of plasma and brain unbound fractions to assess the extent of brain distribution of 34 drugs: comparison of unbound concentration ratios to in vivo pglycoprotein efflux ratios. Drug Metab Dispos. 2007;35(4):660-6.

31. Selvaggio G, Pearlstein RA. Biodynamics: a novel quasi-_rst principles theory on the fundamental mechanisms of cellular function/ dysfunction and the pharmacological modulation thereof. PLoS One. 2018;13(11):e0202376.

32. Zhao R, Pollack GM. Regional diferences in capillary density, perfusion rate, and P-glycoprotein activity: a quantitative analysis of regional drug exposure in the brain. Biochem Pharmacol. 2009;78(8):1052-9.

33. Smith DA. Metabolism, pharmacokinetics and toxicity of functional groups: impact of chemical building blocks on ADMET. Royal Society of Chemistry. 2010.

34. Vauquelin G. Effects of target binding kinetics on in vivo drug efficacy: koff, kon and rebinding. Br J Pharmacol. 2016;173(15): 2319-34.

35. de Witte WEA, Danhof M, van der Graaf PH, de Lange ECM. In vivo target residence time and kinetic selectivity: The association rate constant as determinant. Trends Pharmacol Sci. 2016;37(10): 831-42.

36. Potschka H, Baltes S, Fedrowitz M, Löscher W. Impact of seizure activity on free extracellular phenytoin concentrations in amygdalakindled rats. Neuropharmacology. 201 1;61(5-6):909-17.

37. Marchi N, Betto G, Fazio V, Fan Q, Ghosh C, Machado A, et al. Blood-brain barrier damage and brain penetration of antiepileptic drugs: role of serum proteins and brain edema. Epilepsia. 2009;50(4):664-77.

38. Chabner BA, Allegra CJ, Curt GA, Clendeninn NJ, Baram J, Koizumi S, et al. Polyglutamation of methotrexate. Is methotrexate a prodrug? J Clin Invest. 1985;76(3):907-12.

Publisher's Note Springer Nature remains neutral with regard to jurisdictional claims in published maps and institutional affiliations. 